Technische

Universität

Berlin

Philipp König, Kartik Anand, Frank Heinemann

\title{
Guarantees, transparency and the interdependency between sovereign and bank default risk
}

Open Access via institutional repository of Technische Universität Berlin

\section{Document type}

Journal article | Accepted version

(i. e. final author-created version that incorporates referee comments and is the version accepted for publication; also known as: Author's Accepted Manuscript (AAM), Final Draft, Postprint)

This version is available at

https://doi.org/10.14279/depositonce-15083

\section{Citation details}

König, P., Anand, K. and Heinemann, F. (2014). Guarantees, transparency and the interdependency between sovereign and bank default risk. Journal of Banking \& Finance, Volume 45, 2014, pp. 321-337, https://doi.org/10.1016/j.jbankfin.2014.03.007.

\section{Terms of use}

()(1) $(\odot)$ This work is licensed under a Creative Commons Attribution-NonCommercial- NoDerivatives 4.0 International license: https://creativecommons.org/licenses/by-nc-nd/4.0/ 


\title{
Guarantees, transparency and the interdependency between sovereign and bank default risk
}

\author{
Philipp König ${ }^{a, *}$, Kartik Anand ${ }^{\mathrm{b}}$, Frank Heinemann ${ }^{\mathrm{c}}$ \\ ${ }^{a}$ DIW Berlin, Department of Macroeconomics, Mohrenstraße 58, 10117 Berlin, Germany \\ ${ }^{b}$ Financial Stability Department, Bank of Canada, Ottawa, Ontario, Canada K1A 0G9 \\ ${ }^{c}$ Technische Universität Berlin, Sek. H 52, Straße des 17. Juni 135, 10623 Berlin, Germany
}

\begin{abstract}
Bank debt guarantees have traditionally been viewed as costless measures to prevent bank runs. However, as recent experiences in some European countries have demonstrated, guarantees may link the coordination problems of bank and sovereign creditors and induce a functional interdependence between the likelihoods of a government default and bank illiquidity. Employing a global-game approach, we model this link, showing the existence and uniqueness of the joint equilibrium and derive its comparative statics properties. In equilibrium, the guarantee reduces the probability of a bank run, while it increases the probability of a sovereign default. The latter erodes the guarantee's credibility and thus its effectiveness ex ante. By setting the guarantee optimally, the government balances these two effects in order to minimize expected costs of crises. Our results show that the optimal guarantee has clear-cut welfare gains which are enhanced through policies that promote greater balance sheet transparency.

Keywords: bank debt guarantees, transparency, bank default, sovereign default, global games

JEL classification codes: G01, G28, D89
\end{abstract}

\footnotetext{
The views expressed herein are those of the authors and do not represent the official views of the Bank of Canada. We are grateful to Christian Basteck, Adam Lederer, Frank Milne, Gurnain Pasricha, Charlotte Senftleben and TengTeng $\mathrm{Xu}$ for helpful comments and suggestions for improvement. The comments of participants at the 47th Annual Conference of the Canadian Economic Association (Montréal, 30 May-2 June 2013), Conference on Global Financial Stability and Prosperity (Sydney, 4-5 July 2013), seminar participants at the Bank of Canada, DIW, Norges Bank and University of Auckland are also gratefully acknowledged. The authors also acknowledge support of the Deutsche Forschungsgemeinschaft through the Collaborative Research Center (Sonderforschungsbereich) SFB 649 on "Economic Risks". All remaining errors are our own.

*Corresponding author: pkoenig@diw.de
} 


\section{Introduction}

\subsection{Motivation}

Following the collapse of Lehman Brothers in September 2008, a great many, in particular European, countries issued sizable bank debt guarantee programs to stave off bank runs. The prevailing popularity of such schemes was rooted in the widely held belief that they were largely costless measures. For example, one may argue on grounds of the seminal model by Diamond and Dybvig (1983) that the credible promise of a bank liability guarantee alone would suffice to keep bank creditors from running the bank, so that the guarantee would in fact never be paid out. But such considerations usually abstract from potential funding problems of the government, thereby implicitly assuming that the guarantee is perfectly credible. However, given the enormous size of some of the recent guarantee schemes, the question arises whether these guarantees can in fact be considered as financially viable and therefore credible. If the government has to pay out the guarantee following the bank's default, this would impinge on its finances, which in turn would deter sovereign creditors from continuing to finance the government. This would erode the guarantee's credibility. Or, as one market participant put it in the Wall Street Journal (2011) with respect to the euro area crisis, "How useful would bank guarantees from [euro area] member states be if these member states are themselves shut out of financial markets?"

In this paper, we analyze conditions conducive for the success of bank debt guarantee schemes. We model the coordination problem between a bank's creditors and sovereign creditors that arises from the government's guarantee of the bank creditors' claims. The guarantee induces a functional interdependence between the likelihood of a sovereign default and a banking crisis which crucially depends on the transparency of bank and government. By applying the global games approach, we derive the impact of guarantee programs on the ex ante probabilities of bank and sovereign defaults as well as on the likelihood of a simultaneous default. Assuming that such defaults are associated with welfare losses, we consider the optimal guarantee that minimizes expected welfare costs and we analyze how the optimal guarantee scheme is affected by the transparency of bank balance sheets and government finances.

Fig. 1 further motivates our analysis of guarantee schemes and the resulting relationship between bank and sovereign default risk. Panel 1(a) shows the increases in bank and sovereign CDS premia (as a measure for default risks) during the financial crisis in different countries prior to the introduction of bank debt guarantees. Increases in sovereign default risk were rather small compared to the massive increase in banking sector risks. Prompted into action, governments issued bank debt guarantees in order to strengthen their domestic banking sectors. The size of these schemes relative to the respective countries' gross national product (GDP) is shown in Panel 1(b). While the schemes in Italy, Spain and Portugal amounted to about 3 percent, 9 percent and 12 percent of GDP, respectively, in Austria and the Netherlands they totaled roughly 30 percent of GDP. Albeit sizable, these programs were dwarfed by the comprehensive guarantee introduced by Ireland, which amounted to roughly 193 percent of GDP. In most circumstances, the guarantees were indeed successful in alleviating default risks within domestic banking sectors. Yet, they led to, albeit smaller, increases in sovereign default risk for the issuing governments as shown in Panel 1(c). This suggests that the guarantees not only led to a reallocation of risk from banks to governments, but they may also have contributed towards reducing economy-wide risks. However, in the euro area crisis countries Ireland, Spain, Italy and Portugal, the guarantees were apparently not sufficient to stop the protracted funding drains from these countries' banking sectors as 
Figure 1: Stylized Facts

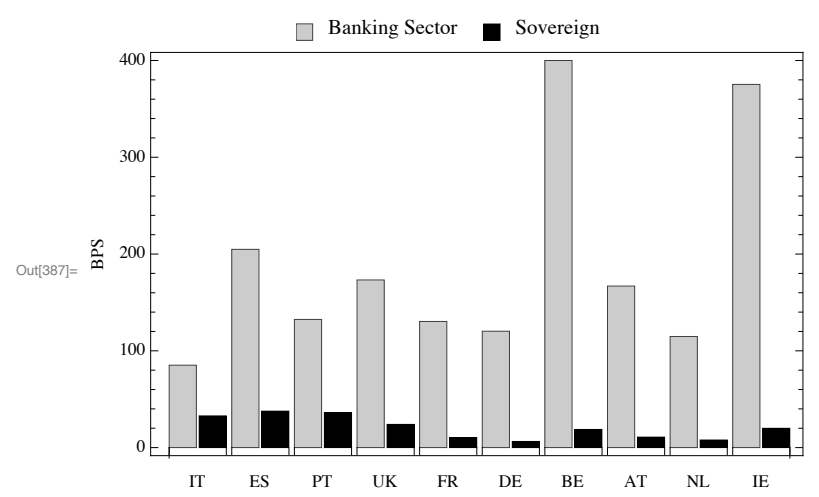

Panel (a): Change in CDS spreads for banks and sovereigns between 1 January 2007 and 25 September 2008. Bank CDSs are unweighted averages of banks with headquarters in respective countries. Source: Bloomberg.

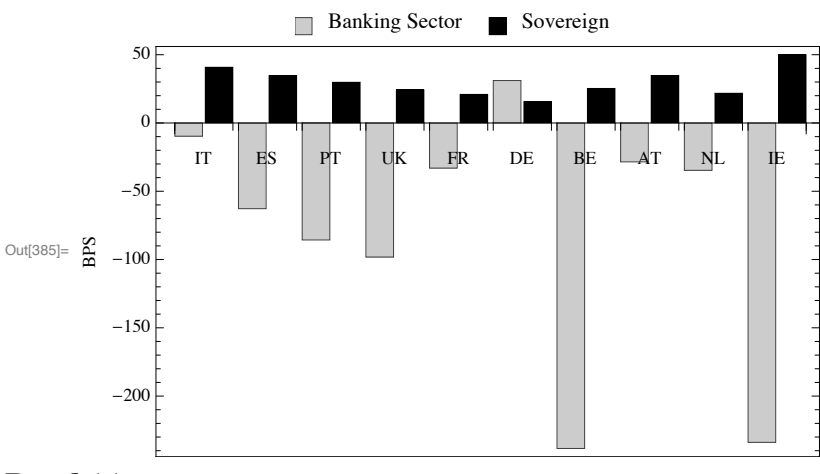

Panel (c): Change in CDS spreads for banks and sovereigns between 26 September 2008 and 21 October 2008. Bank CDSs are unweighted averages of banks with headquarters in respective countries. Source: Bloomberg.

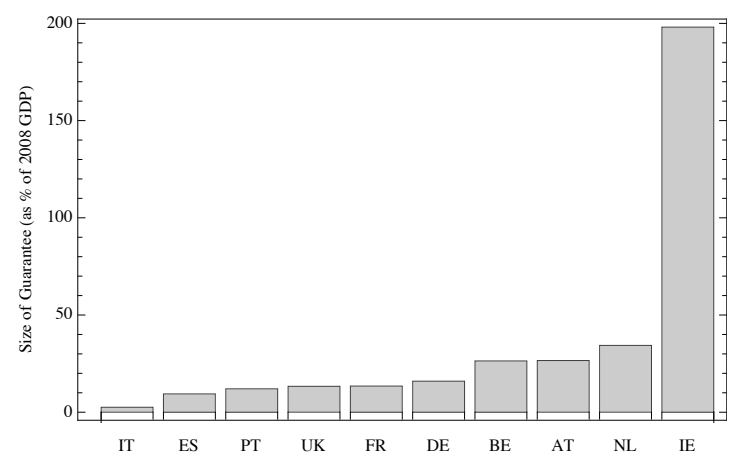

Panel (b): Guarantee sizes in \% of GDP. Source: European Commission, OECD and Levy and Schich (2010).

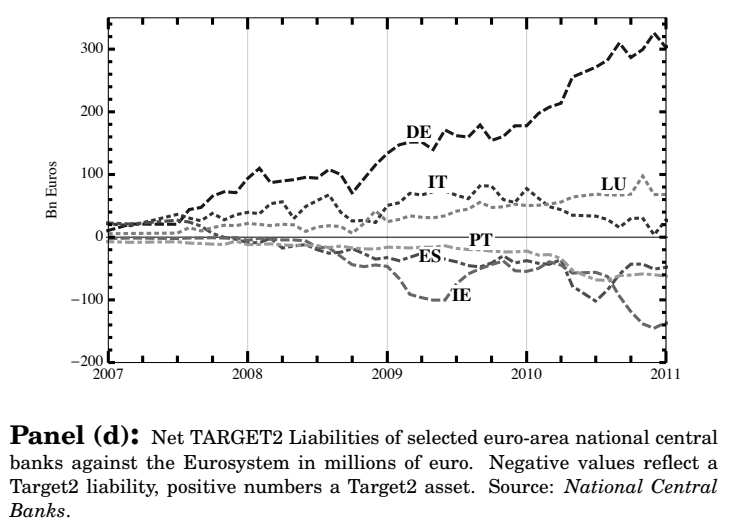

can be seen from these countries' Target balances shown in Panel 1(d). ${ }^{1}$ Moreover, in the case of Ireland, the overly large guarantee burden contributed to the ensuing financing problems of its government, forcing the country to seek financial support from the IMF and EU in late 2010. ${ }^{2}$ Hence, the crisis that ensnared Ireland ran counter to the beliefs held by many with regards to how bank debt guarantee schemes should actually operate.

\subsection{Preview of the Paper}

In our model, bank and sovereign creditors simultaneously decide whether to roll over their respective claims or to withdraw. By introducing a credible guarantee scheme, the government provides incentives for bank creditors to continue financing the bank and thereby reduces the likelihood of a bank run. Yet, in case the bank is run despite the provision of the guarantee, the government faces additional financial strains. Anticipating this situation, sovereign creditors become more reluctant to roll over their claims against the government. This, in turn, increases the likelihood that the government defaults.

By using the global games approach, we solve for the unique monotone (or threshold) equilibrium. Moreover, we prove that there are no other equilibria in non-threshold strategies. Essentially, the guarantee lowers the likelihood of a banking crisis because

\footnotetext{
${ }^{1}$ For Italy, where guarantees were small compared to other crisis countries, Target balances became negative not until 2011.

${ }^{2}$ See Honohan (2010) for details on the Irish banking and sovereign crisis and Levy and Schich (2010) for an overview of government guarantees during the recent crisis.
} 
it reduces the strategic uncertainty on the side of bank creditors; yet, this comes at the expense of higher uncertainty of government creditors, since the guarantee introduces the possibility that creditors of both, bank and government, coordinate on withdrawing their funds. As will be shown in the comparative statics results, if the guarantee becomes too large, its credibility may be eroded to such an extent that further increases in the guarantee size raises the likelihood of bank runs instead of reducing it.

Assuming that the default of bank and government induce welfare losses for the economy as a whole, we derive the optimal guarantee that minimizes total expected welfare costs. The optimal guarantee trades off the effects of a lower likelihood of bank default and a higher likelihood of sovereign default, weighted with the respective social costs. The magnitude of the optimal risk transfer between bank and government crucially depends on the transparency of the bank's and the government's balance sheets. Moreover, owing to the non-zero probability of sovereign default, even an optimal guarantee cannot establish the first-best solution where fundamentally solvent banks may never become illiquid due to a creditor run.

Although the government in the model wishes to avoid a bank default, we abstract away from direct payments being made by the solvent bank to the government. If, for example, the government could collect taxes from the bank, its liquidity situation would be directly intertwined with the bank. However, such taxes would also distort the incentives of the bank to act prudently which would complicate the model and blur the effects of strategic uncertainty. Instead, we concentrate on the 'pure' strategic interaction between the bank's and the government's creditors.

In section 4 , we employ numerical methods to investigate how the optimal guarantee size and its welfare properties are related to the underlying model parameters. The optimal guarantee is obtained by minimizing a cost-of-crisis function, which is a weighted sum of the welfare losses attributed to individual bank and government defaults and to a joint crisis. Policies that improve balance-sheet transparency allow for higher guarantees and are welfare enhancing. The size of the optimal guarantee decreases when the banking sector faces a larger liquidity mismatch. But, the welfare gains from issuing the optimal guarantee are increasing in the size of the bank's liquidity mismatch. Finally, on grounds of our numerical results, we put forth an explanation why empirically, the reduction in banking sector CDS spreads that followed the introduction of guarantee schemes was often larger in absolute magnitude than the accompanying increase in sovereign CDS spreads (see Panel 1(c)). We argue that the strong reduction in banking sector CDSs may have been due to the guarantee's effect of removing strategic uncertainty among bank creditors, while the higher sovereign CDSs are attributed to the opacity of the bank's balance sheets.

\section{Relation to the Literature}

Our model builds on the work of Morris and Shin (2000), Rochet and Vives (2004) and Goldstein and Pauzner (2005) who use the global game methodology of Carlsson and van Damme (1993) and Morris and Shin $(1998,2003)$ in order to derive a unique equilibrium in bank run models that would otherwise exhibit the classical multiple equilibria problem of Diamond and Dybvig (1983).

Bebchuk and Goldstein (2010) consider a similar, stylized global game model, where banks may fail to coordinate on lending to the non-financial sector. Among other policy measures, they consider how a guarantee of banks' loans could overcome the no-lending or credit-freeze equilibrium. Similar to the effect of a deposit insurance in a bank-run model, they find that when the guarantee is sufficiently high, the risk of coordination 
failure may be reduced to zero. Bebchuk and Goldstein focus on the 'global game selection' for vanishing fundamental uncertainty and conclude that guarantees may eliminate the risk of a credit freeze without any actual cost being spent. Yet, they acknowledge that the validity of this mechanism depends crucially on the credibility of the government that is taken for granted in their model. We fill this void by introducing a refinancing problem for the sovereign guarantor and analyze the global game solution for non-vanishing uncertainty. While this complicates the model, the advantage of our approach is that it allows to study explicitly how strategic uncertainty erodes the credibility of government guarantees. Bebchuk and Goldstein's conclusions still hold whenever fundamental uncertainty vanishes. But whenever bank creditors face some fundamental uncertainty, the guarantee leads to a higher default risk of the sovereign which renders the guarantee less credible.

Allen et al. (2013) derive the size of an optimal guarantee from a moral hazard approach. In setting the guarantee, the government faces a trade-off between a lower likelihood of bank default on the one hand, and higher investments by the bank into risky projects on the other hand. As Bebchuk and Goldstein (2010), they focus on the global game selection for vanishing noise. Thereby, they implicitly assume a perfectly transparent bank and neglect the problem that a too large guarantee may lead to funding problems on the side of the government. While we abstract from the moral hazard problem of Allen et al., the optimal guarantee in our model trades off the reduced risk of bank default against the increased risk of government default.

On the link between banking and sovereign debt crisis, our model also compares to Acharya et al. (2011), who look at how bailouts to the financial sector impact sovereign credit risk. Bank bailouts are financed by taxing the non-financial sector of the economy. While the bailout is successful in alleviating problems of the banks, the higher tax burden of the non-financial sector reduces the economy's growth rate, thus adversely influencing the sovereign's creditworthiness and hence the bailout's credibility. Rather than on bailouts, we focus on a government's guarantee to bank creditors which does not necessarily burden the government's finances.

Finally, our model is technically related to the 'twin crises' global game of Goldstein (2005) that also includes two groups of agents: currency speculators and bank creditors. The former attack a pegged exchange rate, while the latter hold foreign currencydenominated claims against a domestic bank. The (exogenous) political decision by a government to peg the exchange rate connects the actions of the two groups of agents. The greater the fraction of speculators who attack the currency, the more likely a devaluation of the currency becomes, and hence the more likely is the bank to default due to the currency mismatch on its balance sheet. Conversely, the greater the fraction of bank creditors who withdraw their funds, the larger is the outflow of foreign reserves, and it becomes more likely that the currency peg will break down. The actions of bank creditors and speculators are strategic complements. They reinforce each other, giving rise to a vicious circle. In our model, the actions of sovereign and bank creditors are also connected through an exogenous political decision (guaranteeing bank debt). But, in contrast to Goldstein's twin crises theory, bank creditors' actions are strategic substitutes for sovereign creditors. Moreover, in Goldstein's model, the bank's and the sovereign's financial strength are determined by the same fundamental, whilst the financial strength of the respective institutions in our model is driven by different, independently distributed fundamentals. 


\section{Model}

The model describes the simultaneous refinancing problem of a bank (indexed $b$ ) and a government (indexed $g$ ). The key difference between the two refinancing problems is that claims of bank creditors are subject to a (partial) guarantee by the government that they can claim once the bank defaults. Government creditors are not subject to a guarantee. Clearly, the guarantee is paid out in case of bank default only if the government possesses sufficient funds to satisfy both, its own creditors' claims and the guarantee payment. The guarantee thereby connects the refinancing problems of bank and government. Since we are primarily interested in the effects of the linkage created by the government's guarantee promise, we build the model such that absent the guarantee, the two roll-over problems are independent of each other.

Ex ante, the government sets the guarantee optimally by minimizing the expected costs of crises (taken to be the expected output losses that may arise in cases of bank, government or joint default). The sequence of events in the model is as follows:

- Date 0: Government promises a guarantee to bank creditors that minimizes the expected costs of crises.

- Date 1: Bank's and government's liquid resources are drawn independently from their respective distributions. The true realizations remain unknown to the creditors, but they obtain some noisy information about their respective debtor's liquidity. Based on this information and their knowledge about the prior distributions, creditors in both groups decide simultaneously whether to roll over their funds or to withdraw. Conditional on the aggregate withdrawal decisions by their respective creditors, bank and government either continue until date 2 or default. Creditors who decided to withdraw receive their respective payoffs.

- Date 2: Depending on whether default occurred at date 1 or not, creditors who decided to roll over receive their payoffs.

We solve the model backwards by first deriving the equilibrium in the simultaneous roll-over game of bank and government for a given guarantee amount. This in turn allows us to compute the probabilities of bank default, sovereign default and simultaneous default as functions of the guarantee. We then turn to the government's ex ante problem and minimize the expected costs of crises by taking the guarantee's impact on the likelihood of the different types of crises into account.

\subsection{The Debt Roll-Over Game}

Creditors' Payoffs. Bank and government are both indebted to risk-neutral creditors $n_{i} \in\left[0, N_{i}\right], i \in\{b, g\}$. For simplicity, we assume the bank's creditors to be different from the government's creditors. All creditors hold identical claims with a face value of one monetary unit. $N_{b}$ and $N_{g}$ thus measure the bank's and the government's amounts of short-term debt that can be withdrawn. For simplicity, we normalize the mass of sovereign creditors to unity, $N_{g} \equiv 1$.

Creditors in each group have common payoffs. These are summarized in Tables 1 and 2. At date 1 , a creditor can demand his unit claim, whereas at date 2 , in case no default occurred, he is entitled to the unit claim plus accrued interest. Date 1 withdrawal, however, may entail transaction costs for the creditors which are subtracted from the unit claim. 
A sovereign creditor who withdraws at date 1 receives $C_{g} \leq 1$. If he rolls over and the government survives, he receives $D_{g}>1$. If the government defaults, the sovereign creditors who rolled over get a zero payoff (see Table 1).

\begin{tabular}{|c|c|c|c|}
\cline { 3 - 4 } \multicolumn{2}{c|}{} & \multicolumn{2}{c|}{ Government } \\
\cline { 3 - 4 } \multicolumn{2}{c|}{ Sefault } & Survive \\
\hline \multirow{2}{*}{ Sovereign Creditor } & Withdraw & $C_{g}$ & $C_{g}$ \\
\cline { 2 - 4 } & Roll over & 0 & $D_{g}$ \\
\hline
\end{tabular}

Table 1: Typical sovereign creditor's payoffs.

Similarly, a typical bank creditor who withdraws early receives $C_{b}$, which, in order to reduce the number of free parameters in the model, is normalized to unity. This normalization may reflect smaller transaction costs in bank funding markets compared to sovereign debt markets. If the bank creditor rolls over and the bank does not default, he obtains $D_{b}>1$. Yet, in contrast to the sovereign creditors, if the bank defaults at date 1 , a bank creditor becomes entitled to a guarantee $\ell \leq 1$. The guarantee is paid out only if the government does not default as well, otherwise, the bank creditor receives a zero payoff (see Table 2).

\begin{tabular}{|c|c|c|c|c|}
\cline { 3 - 5 } \multicolumn{2}{c|}{} & \multicolumn{2}{c|}{ Bank Default } & \multirow{2}{*}{ Bank Survive } \\
\cline { 3 - 5 } \multicolumn{2}{c|}{} & Govt Survive & Govt Default & \\
\hline \multirow{2}{*}{ Bank Creditor } & Withdraw & $C_{b}=1$ & $C_{b}=1$ & $C_{b}=1$ \\
\cline { 2 - 5 } & Roll over & $\ell$ & 0 & $D_{b}$ \\
\hline
\end{tabular}

Table 2: Typical bank creditor's payoffs.

Bank and Government Default. Whether aggregate withdrawals drive bank or government into default at date 1 depends on their respective access to liquid funds. Here we take a shortcut and assume that available funds are determined randomly. The bank's date 1 balance sheet liquidity is summarized by the random variable $\theta_{b} \sim U\left[\theta_{b}^{0}-\eta_{b}, \theta_{b}^{0}+\right.$ $\eta_{b}$ ], with the ex ante mean being $\theta_{b}^{0}$ and variance being $\eta_{b}^{2} / 3$. Similarly, the government's stock of liquid resources is summarized by the random variable $\theta_{g} \sim U\left[\theta_{g}^{0}-\eta_{g}, \theta_{g}^{0}+\eta_{g}\right]$ with the ex ante mean and variance $\theta_{g}^{0}$ and $\eta_{g}^{2} / 3 .{ }^{3}$ With respect to the relation between $\theta_{b}$ and $\theta_{g}$, we impose the following assumption.

Assumption: The government's liquidity, $\theta_{g}$, and the bank's liquidity, $\theta_{b}$, are independently distributed.

Whether or not the bank or the government default, depends on their realized recourse to liquidity and on the number of creditors who withdraw. Denote by $\lambda_{b} \in[0,1]$

\footnotetext{
${ }^{3} \theta_{b}$ can be thought to consist of two parts. First, there are the liquid assets on the bank's balance sheet, that directly contribute to increasing $\theta_{b}$. Second, the bank can raise cash by entering into secured finance arrangements - for example, repurchase agreements and covered bonds - where it pledges illiquid assets to investors in exchange for cash. These investors, who are not explicitly modelled, include other commercial banks, hedge funds, and also the central bank. $\theta_{g}$ can be interpreted as the stock of liquid assets of the government, including its amount of cash holdings or redeemable deposits, assets that can be easily liquidated given actual legal and political constraints.
} 
the fraction of bank creditors who withdraw. The bank defaults whenever aggregate withdrawals exceed its available liquid resources, i.e.

$$
\lambda_{b} N_{b} \geq \theta_{b}
$$

The government's default condition also depends on whether the bank defaults and some of its creditors mistakenly roll over, thereby becoming benefactors of the guarantee. Hence, we distinguish between two cases. If the bank does not default and no guarantee payments have to be made, the government defaults whenever

$$
\lambda_{g} \geq \theta_{g}
$$

If the bank defaults, the default condition of the government becomes

$$
\lambda_{g}+\ell\left(1-\lambda_{b}\right) N_{b} \geq \theta_{g}
$$

where the second term now reflects the guarantee payments that have to be made to the $\left(1-\lambda_{b}\right) N_{b}$ bank creditors who mistakenly rolled over.

Information and Strategies. We assume that the liquidity parameters $\theta_{b}$ and $\theta_{g}$ are unknown to creditors until the end of date 2. Yet, creditors know the prior distributions and, in addition, they receive private signals about their respective debtor's liquidity at date 1 . Specifically, a typical creditor $n_{i}$ receives a signal $x_{n_{i}}=\theta_{i}+\varepsilon_{n_{i}}$, where $\varepsilon_{n_{i}}$ is an idiosyncratic i.i.d. noise term, uniformly distributed over $U\left[-\varepsilon_{i}, \varepsilon_{i}\right]$. Creditors use their private signals and the commonly known prior to form individual posteriors $\left.\theta_{i}\right|_{x_{n_{i}}}$ by means of Bayesian updating. Furthermore, we assume that the signals of bank and sovereign creditors are completely uninformative about the fundamental of the respective other entity. Following the literature on transparency (i.e., Heinemann and Illing (2002); Bannier and Heinemann (2005); Lindner (2006)), the parameters $\varepsilon_{b}$ and $\varepsilon_{g}$ can be interpreted as the degrees of (balance-sheet) transparency of bank and government resepctively. When these values are small, transparency is high since the signals enable creditors to more accurately infer the true $\theta_{i}$ from their signal observations.

A strategy for a typical creditor is specified as a complete plan of action that determines for each realization of the signal whether the creditor rolls over or withdraws. Formally, a strategy is a mapping $s_{n_{i}}: x_{n_{i}} \mapsto\{0,1\}$, where 1 stands for withdrawal and 0 for roll over. Strategies are symmetric if $s_{n_{i}}(\cdot)=s_{i}(\cdot)$ for all $n_{i}$. A strategy is called a threshold strategy if a creditor chooses to withdraw for all $x_{n_{i}}$ below some critical $\hat{x}_{n_{i}}$ and rolls over otherwise. Finally, a symmetric threshold strategy is a threshold strategy where all creditors use the same critical $\hat{x}_{i}$.

Moreover, and in particular to apply the global game solution techniques below, we assume that the support of the distributions is large enough to encompass states where all creditors consider withdrawing or rolling over to be dominant strategies, i.e.

$$
\left[-2 \varepsilon_{b}, N_{b}+2 \varepsilon_{b}\right] \subset\left[\theta_{b}^{0}-\eta_{b}, \theta_{b}^{0}+\eta_{b}\right] \text { and }\left[-2 \varepsilon_{g}, \ell N_{b}+N_{g}+2 \varepsilon_{g}\right] \subset\left[\theta_{g}^{0}-\eta_{g}, \theta_{g}^{0}+\eta_{g}\right] .
$$

The first inclusion states that the support of $\theta_{b}$ includes states where all bank creditors receive either very low or very high signals such that they consider withdrawing or rolling over the dominant action. The second inclusion carries a similar interpretation. Yet, the upper range of $\theta_{g}$ must also be sufficiently large to include states where government creditors consider rolling over dominant even though all bank creditors would receive a guarantee. This explains why $\ell N_{b}$ occurs in the subset in the second inclusion. 
Equilibrium. A symmetric equilibrium of the simultaneous bank and government rollover game is given by a pair of strategies $s_{b}(\cdot)$ and $s_{g}(\cdot)$ and aggregate choices $\lambda_{b}\left(\theta_{b}\right)$ and $\lambda_{g}\left(\theta_{g}\right)$ such that bank and sovereign creditors maximize their expected payoffs and

$$
\lambda_{i}\left(\theta_{i}\right)=\frac{1}{2 \varepsilon_{i}} \int_{\theta_{i}-\varepsilon_{i}}^{\theta_{i}+\varepsilon_{i}} s_{i}\left(x_{n_{i}}\right) \mathrm{d} x_{n_{i}} .
$$

Absent a guarantee $(\ell=0)$, the two roll-over problems are independent of each other. It is a well-established result that in this case the two games exhibit a unique equilibrium in symmetric threshold strategies. ${ }^{4}$

However, once the government issues a guarantee $(\ell>0)$, it ties its refinancing problem to the bank's roll-over problem. For realizations of $\theta_{b}$ where the bank defaults, the government faces additional costs due to the guarantee payout. This in turn affects the behavior of its creditors in all states of the world, even in those where the bank survives. Moreover, the possibility that the government may pay out a guarantee affects the behavior of the bank creditors. They become less reluctant to roll over their funds because even if they mistakenly roll over, a part of their loan will be covered by the government's guarantee provided that the government does not default as well. Even though the rollover problems are connected in this way, the assumption that $\theta_{b}$ and $\theta_{g}$ are independent implies that a bank (sovereign) creditor's signal is informative only about the liquidity situation of the bank (sovereign) and completely uninformative about the liquidity of the sovereign (bank). We can therefore treat the behavior of sovereign creditors in the bank roll-over game as exogenously given and vice versa. This allows us to prove that the joint refinancing game with a positive guarantee also has a unique equilibrium in threshold strategies. The following proposition summarizes this result.

Proposition 1. There exists a unique equilibrium where sovereign and bank creditors use threshold strategies. There are no other equilibria in non-threshold strategies.

Proof. See the appendix.

Derivation of the Simultaneous Threshold Equilibrium. As a consequence of Proposition 1 , we restrict our attention to threshold strategies for sovereign and bank creditors. We derive the equilibrium by first solving for the bank's and the government's default conditions. Secondly, we exploit the indifference of agents at the threshold signal.

We begin by deriving the default condition of the bank. Suppose that bank creditors use a threshold strategy around $\hat{x}_{b}$. Conditional on $\theta_{b}$, the signals are independent and by the law of large numbers, the probability that a single creditor observes a signal below $\hat{x}_{b}$ equals the proportion of creditors who observe signals below the threshold, i.e. $\lambda_{b}$. Using the bank's failure condition (1) we can thus express the bank's default point $\hat{\theta}_{b}$ as a function of the critical signal $\hat{x}_{b}$,

$$
\hat{\theta}_{b}\left(\hat{x}_{b}\right)=\frac{N_{b}\left(\hat{x}_{b}+\varepsilon_{b}\right)}{N_{b}+2 \varepsilon_{b}} .
$$

\footnotetext{
4 The equilibrium in game $i \in\{b, g\}$ can be summarized by $\left(\hat{x}_{i}, \hat{\theta}_{i}\right)$. Creditors withdraw if $x_{n_{i}}<\hat{x}_{i}$ and roll over otherwise. Default occurs if and only if $\theta_{i}<\hat{\theta}_{i}$. It is straightforward to show that for the canonical roll-over games considere here, the thresholds become
}

$$
\hat{x}_{i}=\hat{\theta}_{i}+2 \varepsilon_{i}\left(\frac{\hat{\theta}_{i}}{N_{i}}-\frac{1}{2}\right) \quad \text { and } \quad \hat{\theta}_{i}=\frac{N_{i} C_{i}}{D_{i}} .
$$


The bank fails if and only if $\theta_{b}<\hat{\theta}_{b}\left(\hat{x}_{b}\right)$.

Calculating the government's failure point requires to distinguish between the case where the bank survives $\left(\theta_{b} \geq \hat{\theta}_{b}\right)$ and no guarantee payments have to be made and the case where the bank defaults $\left(\theta_{b}<\hat{\theta}_{b}\right)$ and thus some bank creditors may mistakenly rolled over and claim the guarantee $\ell$.

With respect to the first case, assuming that government creditors use a symmetric threshold strategy around $\hat{x}_{g}, \lambda_{g}$ can be expressed as the fraction of sovereign creditors whose signals are below $\hat{x}_{g}$. Using Eq. (2), the government's failure point can be calculated as

$$
\hat{\theta}_{g}\left(\hat{x}_{g}\right)=\frac{\hat{x}_{g}+\varepsilon_{g}}{1+2 \varepsilon_{g}} .
$$

For the second case, note that the government is now obliged to pay $\ell$ to each bank creditor who rolled over his loan. Since bank creditors use a threshold strategy around some $\hat{x}_{b}$, we can calculate total guarantee payments conditional on the realized $\theta_{b}$ as

$$
\ell N_{b} \operatorname{Pr}\left(x_{n_{b}} \geq \hat{x}_{b} \mid \theta_{b}\right)=\frac{\ell N_{b}\left(\theta_{b}+\varepsilon_{b}-\hat{x}_{b}\right)}{2 \varepsilon_{b}} .
$$

Using Eq. (3), the government's failure point can then be calculated by solving

$$
\hat{\theta}_{g}=\frac{\ell N_{b}\left(\theta_{b}+\varepsilon_{b}-\hat{x}_{b}\right)}{2 \varepsilon_{b}}+\frac{\hat{x}_{g}-\hat{\theta}_{g}+\varepsilon_{g}}{2 \varepsilon_{g}}
$$

for $\hat{\theta}_{g}$, yielding

$$
\hat{\theta}_{g}=\frac{\hat{x}_{g}+\varepsilon_{g}}{1+2 \varepsilon_{g}}+\frac{\varepsilon_{g}}{\varepsilon_{b}} \frac{\ell N_{b}\left(\theta_{b}+\varepsilon_{b}-\hat{x}_{b}\right)}{1+2 \varepsilon_{g}} .
$$

Taken together, the government's failure point can be expressed as

$$
\hat{\theta}_{g}\left(\hat{x}_{g}, \hat{x}_{b}, \theta_{b}\right)= \begin{cases}\frac{\hat{x}_{g}+\varepsilon_{g}}{1+2 \varepsilon_{g}} & \text { if } \theta_{b}>\hat{\theta}_{b}\left(\hat{x}_{b}\right) \text { or } \theta_{b}<\hat{x}_{b}-\varepsilon_{b} \\ \frac{\hat{x}_{g}+\varepsilon_{g}}{1+2 \varepsilon_{g}}+\frac{\ell N_{b} \varepsilon_{g}}{\varepsilon_{b}\left(1+2 \varepsilon_{g}\right)}\left(\theta_{b}+\varepsilon_{b}-\hat{x}_{b}\right) & \text { if } \hat{x}_{b}-\varepsilon_{b} \leq \theta_{b} \leq \hat{\theta}_{b}\left(\hat{x}_{b}\right) .\end{cases}
$$

The government defaults if and only if $\theta_{g} \leq \hat{\theta}_{g}\left(\hat{x}_{g}, \hat{x}_{b}, \theta_{b}\right)$.

Given the default points of bank and government in Eqs. (5) and (6), we now turn to the calculation of the expected payoff differences for typical bank and sovereign creditors who observe signals $x_{n_{b}}$ and $x_{n_{g}}$, respectively, and who believe that all other bank and sovereign creditors are using the symmetric threshold strategies around $\hat{x}_{b}$ and $\hat{x}_{g}$.

For the typical bank creditor with signal $x_{n_{b}}$, the expected payoff difference between rolling over and withdrawing is given by

$$
\pi^{b}\left(\hat{x}_{b}, \hat{x}_{g}, x_{n_{b}}\right) \equiv \frac{D_{b}}{2 \varepsilon_{b}}\left(x_{n_{b}}+\varepsilon_{b}-\hat{\theta}_{b}\left(\hat{x}_{b}\right)\right)+\frac{\ell}{2 \varepsilon_{b}} \int_{x_{n_{b}}-\varepsilon_{b}}^{\hat{\theta}_{b}\left(\hat{x}_{b}\right)}\left(\frac{\widetilde{\sigma}_{g}-\hat{\theta}_{g}\left(\hat{x}_{g}, \hat{x}_{b}, u\right)}{\sigma_{g}}\right) \mathrm{d} u-1,
$$

where

$$
\sigma_{g}=2 \eta_{g} \quad \text { and } \quad \widetilde{\sigma}_{g}=\theta_{g}^{0}+\eta_{g}
$$

are the width of the support for the $\theta_{g}$ and the upper bound of the support, respectively. The second summand in Eq. (7) is the payment from the guarantee $\ell$ multiplied by the probability attached by the bank creditor to the survival of the government.

The difference in expected payoffs between rolling over and withdrawing for a typical sovereign creditor with signal $x_{n_{g}}$ is 


$$
\pi^{g}\left(\hat{x}_{g}, \hat{x}_{b}, x_{n_{g}}\right)=\frac{D_{g}}{2 \epsilon_{g}}\left(x_{n_{g}}+\epsilon_{g}-\frac{\hat{x}_{g}+\epsilon_{g}}{1+2 \epsilon_{g}}\right)-\frac{D_{g} \ell N_{b}}{\left(1+2 \varepsilon_{g}\right) \sigma_{b}} \int_{\hat{x}_{b}-\varepsilon_{b}}^{\hat{\theta}_{b}} \frac{u+\varepsilon_{b}-\hat{x}_{b}}{2 \varepsilon_{b}} \mathrm{~d} u-C_{g},
$$

where $\sigma_{b}=2 \eta_{b}$.

From Proposition 1, we know that a unique equilibrium in threshold strategies exists. This implies that if the pair of signals $\left(\hat{x}_{b}, \hat{x}_{b}\right)$ constitutes a threshold equilibrium, creditors who observe signals $\hat{x}_{b}$ and $\hat{x}_{b}$ must be indifferent between rolling over and withdrawing.

Hence, the equilibrium threshold signals must satisfy

$$
\pi^{b}\left(\hat{x}_{b}, \hat{x}_{g}, \hat{x}_{b}\right)=0
$$

as well as $\pi^{b}\left(\hat{x}_{b}, \hat{x}_{g}, x_{n_{b}}\right) \gtrless 0$ if and only if $x_{n_{b}} \gtrless \hat{x}_{b}$, and

$$
\pi^{g}\left(\hat{x}_{g}, \hat{x}_{b}, \hat{x}_{g}\right)=0,
$$

as well as $\pi^{g}\left(\hat{x}_{g}, \hat{x}_{b}, x_{n_{g}}\right) \gtrless 0$ if and only if $x_{n_{g}} \gtrless \hat{x}_{g}$.

An equilibrium of the joint roll-over game is thus a combination of critical signals that simultaneously solve Eqs. (9) and (10). Using the result provided in the following Proposition 2, we explore the properties of the equilibrium by using graphical techniques.

Proposition 2. The solutions to creditors' indifference conditions, Eqs. (9) and (10), can be characterized by functions $f_{b}$ and $f_{g}$, where $\hat{x}_{b}=f_{b}\left(\hat{x}_{g}\right)$ and $\hat{x}_{g}=f_{g}\left(\hat{x}_{b}\right)$. Moreover, $f_{b}$ is strictly increasing, whereas $f_{g}$ is strictly decreasing.

Proof. See the appendix.

The functions $f_{b}$ and $f_{g}$ can be interpreted as aggregate best response functions between bank and sovereign creditors. The equilibrium of the model is then given by the intersection of the two curves.

Fig. 2 illustrates the equilibrium. The best response curve for bank creditors, $f_{b}$, is strictly increasing over the entire range of $\hat{x}_{g}$, implying that the actions of sovereign creditors are strategic complements for bank creditors. As sovereign creditors increase their critical signal, the risk of a government default increases and the credibility of the guarantee decreases. In response, bank creditors increase their critical signal as well. In contrast, $f_{g}$ is strictly decreasing over the entire range of $\hat{x}_{b}$, implying that the actions of bank creditors are strategic substitutes for sovereign creditors. This deserves further comment. Suppose that bank creditors increase their critical signal $\hat{x}_{b}$. This exerts two opposing effects on sovereign creditors' payoffs and thus on their critical signal $\hat{x}_{g}$. Firstly, a higher $\hat{x}_{b}$ increases $\hat{\theta}_{b}$ and enlarges the range of $\theta_{b}$ realizations where the bank may default and the guarantee comes due. This, in turn, decreases sovereign creditors' expected payoffs from rolling over and induces them to increase their critical signal as well. This effect is, up to a constant, given by ${ }^{5}$

$$
\left(\hat{\theta}_{b}+\varepsilon_{b}-\hat{x}_{b}\right) \frac{\partial \hat{\theta}_{b}}{\partial \hat{x}_{b}}
$$

\footnotetext{
${ }^{5}$ The formal derivation of is provided in the proof of Proposition 2 and specifically Eq. (A6) in the appendix.
} 
Figure 2: Best reply curves $f_{b}$ and $f_{g}$. The joint equilibrium in the roll-over games occurs at the intersection point $\left(\hat{x}_{b}^{*}, \hat{x}_{g}^{*}\right)$.

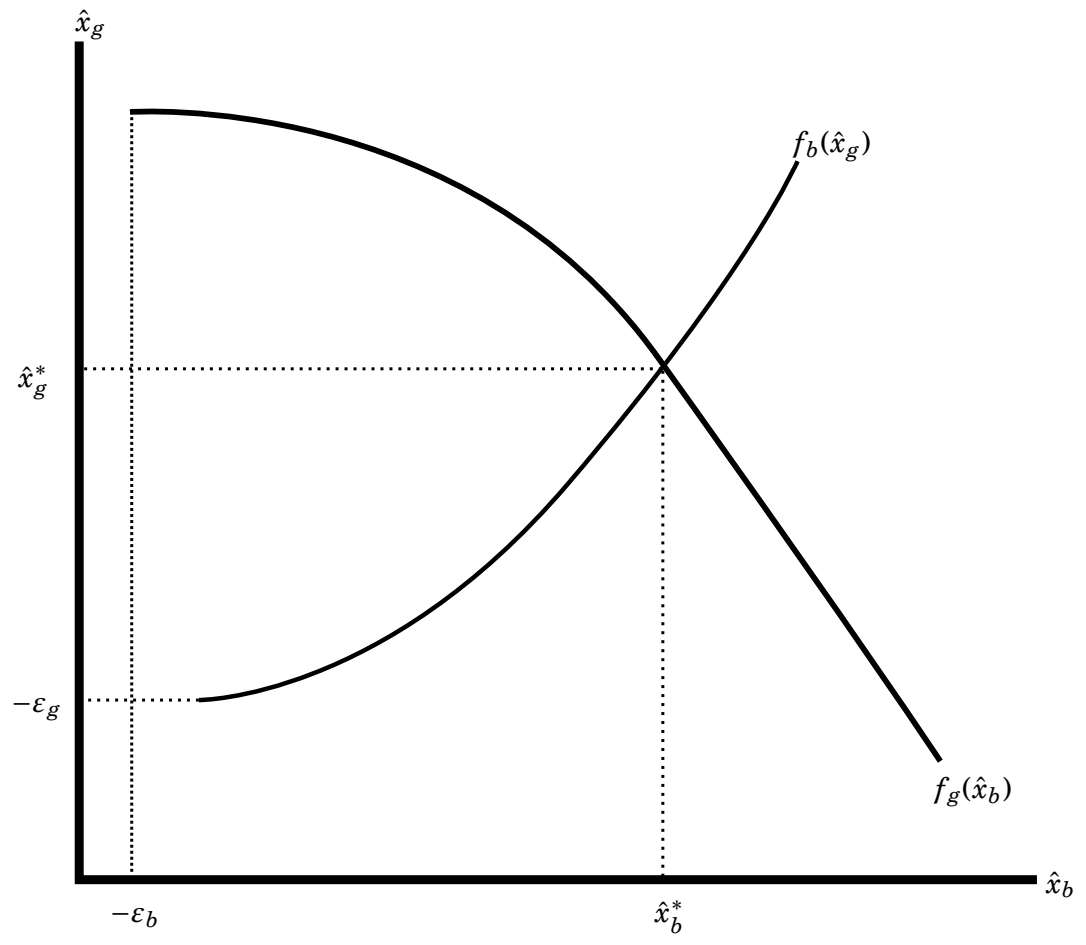

However, a second, opposing effect exists. An increase in $\hat{x}_{b}$ implies that for any given $\theta<\hat{\theta}_{b}$ fewer bank creditors mistakenly roll over their debt whenever the bank fails. Consequently, the guarantee payout by the government is lowered. In turn, the likelihood that the government survives rises and a typical sovereign creditor's expected payoff from rolling over increases. Formally, this effect is, up to the same constant, given by

$$
-\left(\hat{\theta}_{b}+\varepsilon_{b}-\hat{x}_{b}\right)
$$

The second effect outweighs the first one as long as $\varepsilon_{b}>0$, since

$$
\frac{\partial \hat{\theta}_{b}}{\partial \hat{x}_{b}}=\frac{N_{b}}{N_{b}+2 \varepsilon_{b}}<1
$$

This implies that sovereign creditors' expected payoff from rolling over increases with a higher critical signal of bank creditors, thus leading to the downward-sloping aggregate best response curve for sovereign creditors.

\subsection{Comparative statics}

We next analyze the comparative statics properties of the critical signals with respect to the guarantee size $\ell$, the size of the bank's short-term exposure $N_{b}$ and the ex ante expected recourse to liquidity $\theta_{b}^{0}$ and $\theta_{g}^{0}$ for the bank and the government, respectively. In the main text we resort to a graphical presentation. The analytical comparative statics can be found in Lemma 4 in the appendix. ${ }^{6}$

\footnotetext{
${ }^{6} \mathrm{As}$ is common in the literature on global games, we restrict comparative statics to marginal changes of parameters that satisfy the conditions for existence and uniqueness of equilibrium. Here, condition (4), guaranteeing the existence of dominance regions, is crucial. Without well-defined dominance regions, the equilibrium is not unique anymore. While the threshold equilibrium derived above still exists, there may
} 
Changes to guarantee size. Fig. 3 depicts the marginal rate of substitution between the amount of the guarantee $\ell$ and the perceived liquidity of the bank conditional on the change in sovereign risk. The increase shifts the $f_{b}$ curve to the left. For any given $\hat{x}_{g}$, a higher guarantee increases bank creditors' expected payoff from rolling over and lowers their critical signal. The $f_{g}$ curve is shifted to the right. For any given $\hat{x}_{b}$, a higher guarantee lowers the probability that the government survives and, in response, sovereign creditors raise their critical signal. The increase in the guarantee thereby exerts a direct effect on the payoffs for both bank and sovereign creditors. In addition, it exerts an indirect effect through the change in the critical signal of the respective other type of creditors. For sovereign creditors, both effects work in the same direction and produce a clear-cut total effect. For bank creditors, the two effects work in opposite directions. An increase in the critical signal of sovereign creditors lowers bank creditors' expected payoffs from rolling over and thereby countervails the positive effect of the higher guarantee. If, however, the rightward shift in the $f_{g}$ curve is sufficiently small, then the latter effect outweighs the former and bank creditors' critical signal is lowered. The following proposition provides a necessary and sufficient condition for this to occur.

Proposition 3. A marginal increase in the guarantee lowers bank creditors' critical signals and the probability of a banking crisis if and only if

$$
\frac{\ell N_{b}}{\sigma_{b}} \int_{\hat{x}_{b}-\varepsilon_{b}}^{\hat{\theta}_{b}} \frac{u+\varepsilon_{b}-\hat{x}_{b}}{2 \varepsilon_{b}} \mathrm{~d} u<\widetilde{\sigma}_{g}-\hat{\theta}_{g}\left(\hat{\theta}_{b}\right) .
$$

Proof. For the effect of the guarantee size on the critical threshold, $\mathrm{d} \hat{x}_{b} / \mathrm{d} \ell$, see proof of Lemma 4 in the appendix. The probability of a banking crisis rises with an increasing critical signal according to Eq. (5).

The left-hand side of condition (11) is the ex ante expected guarantee payout, conditional on the government surviving. The right-hand side is the difference between the government's maximal cash flow (i.e., the upper bound $\widetilde{\sigma}_{g}$ of the support for $\theta_{g}$ ) and the minimal cash flow it needs to survive, which may be interpreted as the slack in available liquidity of the government.

According to Proposition 3, a marginal increase in the guarantee induces bank creditors to decrease their critical signal if and only if the ex ante expected guarantee payout is less than the government's slack in liquidity. Condition (11) can thus be interpreted as a credibility condition: A guarantee $\ell=\tilde{\ell}$ is credible if condition (11) is satisfied when evaluated at $\ell=\tilde{\ell}$. If the condition fails to hold, bank creditors may ex ante judge the government's resources to be insufficient to cover the guarantee promise and respond by raising their critical signal. This also leads to an increase in the probability of a banking crisis. It is straightforward to show that the condition always holds for $\ell=0$, implying that the introduction of a small guarantee is always credible and lowers the probability of a banking crisis. However, as the following corollary states, if a guarantee is credible, then further increases in the guarantee may lead to a reversal of the condition. By increasing the expected burden on the government's available liquidity, the guarantee erodes its own credibility.

also exist other self-fulfilling equilibria. In particular, a large increase in the guarantee size or in the exposure to short-term debt, as well as a large decrease in ex ante expected liquidity, such that restriction (4) is violated, open he door for self-fulfilling crises besides the equilibrium threshold derived above. Large increases in the variance or of private signals or reductions in the variance of liqudity may result in multiple equilibria on both sides of the thresholds. 
Corollary 1. Suppose condition (11) is satisfied for a given guarantee $\tilde{\ell}$. A further marginal increase in the guarantee increases the ex ante expected guarantee payout and simultaneously diminishes the government's slack in liquidity.

Proof. See appendix.

Figure 3: Change in $\left(\hat{x}_{b}^{*}, \hat{x}_{g}^{*}\right)$ due to increase in guarantee from $\ell$ to $\ell^{\prime}$, given that (11) holds.

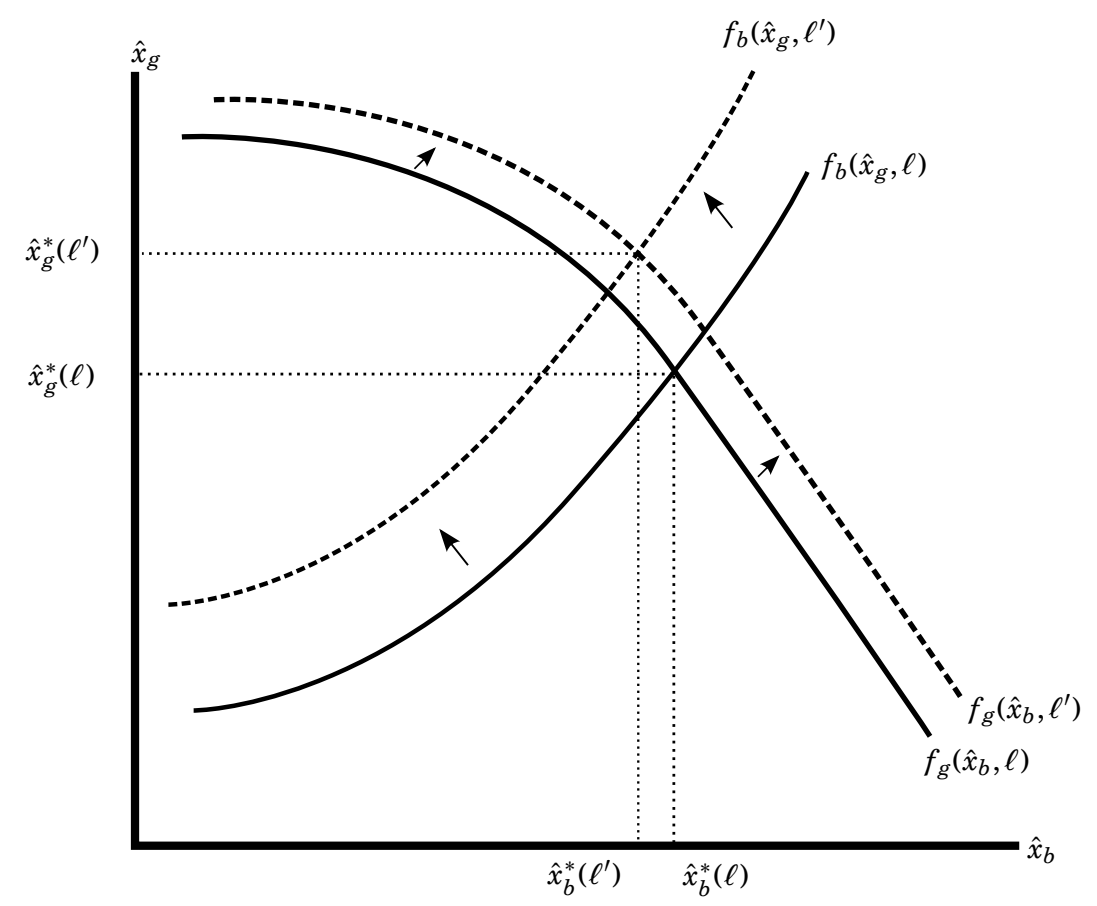

Changes in the bank's exposure to short-term debt. Fig. 4 depicts the effect of an increase in the bank's exposure to short-term debt, $N_{b}$. A higher exposure is associated with a higher probability of bank failure and consequently with larger expected guarantee payments. Thus, increases in $N_{b}$ shift both the $f_{b}$ and $f_{g}$ curves to the right. This leads to a higher critical signal for bank creditors. From the graphical analysis alone, the sign of the effect on the sovereign creditors' critical signal is not clear-cut. On the one hand, a larger $N_{b}$ increases the ex ante guarantee payments, which diminishes the government's liquidity and increases the critical signal for sovereign creditors (given $\ell$ and $\hat{x}_{b}$ ). However, as a consequence of strategic substitutability, a higher critical signal for bank creditors makes sovereign creditors more willing to roll over, thereby mitigating the effect on the sovereign creditors' critical signal. As shown in Lemma 4 in the appendix, the latter 'substitutability effect' is smaller in magnitude than the former 'complementarities effect', implying that a larger $N_{b}$ always leads to an increase in the sovereign creditors' critical signal.

Changes in the expected balance sheet liquidity. Fig. 5 shows the effect of an increase in the government's ex ante expected balance sheet liquidity, $\theta_{g}^{0}$. An increase in $\theta_{g}^{0}$ leaves the $f_{g}$ curve unaffected and shifts $f_{b}$ to the left, thereby lowering bank creditors' and increasing sovereign creditors' critical signal. The decisions of government creditors are based on updated information on $\theta_{g}$ obtained from the signals $x_{n_{g}}$ which do not depend on $\theta_{g}^{0}$. Bank creditors, however, do not receive information updates about $\theta_{g}$ and rely on their knowledge of the government's ex ante expected liquidity. And since an increase 
Figure 4: Change in $\left(\hat{x}_{b}^{*}, \hat{x}_{g}^{*}\right)$ due to an increase in short-term debt from $N_{b}$ to $N_{b}^{\prime}$.

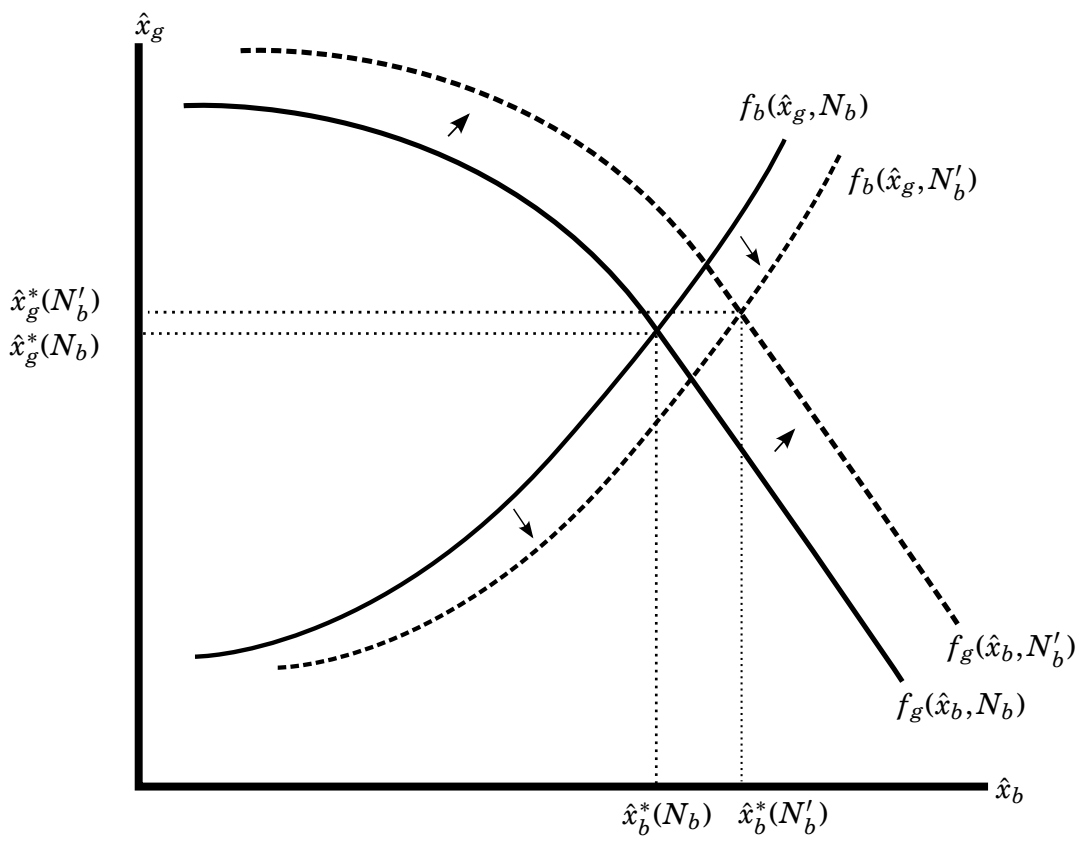

in $\theta_{g}^{0}$ raises the likelihood that the government manages to roll over its debt (and thus raises the probability that the guarantee can be paid out), bank creditors lower their critical signal. However, since the actions of bank creditors are strategic substitutes for sovereign creditors, the critical signal of sovereign creditors rises.

In contrast, an increase in the bank's ex ante expected liquidity $\theta_{b}^{0}$ has no effect on the threshold signals. The reason for this result is twofold. At date 1 , a change in $\theta_{b}^{0}$ does not affect bank creditors' expected payoffs since these are based on their respective posterior distributions unaffected by the ex ante mean of the distribution. Interestingly, also the sovereign creditors' critical signals are unaffected by the bank's expected liquidity. The marginal sovereign creditor takes into account the expected guarantee payments which are determined by the fraction of bank creditors who roll over despite the bank's default. Due to the uniform distribution assumption, this is not affected by the prior mean and therefore $\theta_{b}^{0}$ does not exert any effect on the critical signals.

These results suggest that whenever the bank and the sovereign are connected through the guarantee promise, a spill-over effect exists from the government's ex ante liquidity to the likelihood that the bank survives. While an improvement in the government's expected liquidity raises bank creditors' incentive to roll over, this comes at the cost of a higher critical signal of sovereign creditors that, in turn, may jeopardize the beneficial effect of the improved $\theta_{g}^{0}$ on the government's likelihood of managing the debt roll-over. ${ }^{7}$

\subsection{The optimal guarantee}

Using the equilibrium of the subgame at date 1 , we can express the ex ante probabilities of bank, government and simultaneous default as functions of the guarantee $\ell$

\footnotetext{
${ }^{7}$ The formal derivation of these results is provided in Lemma 4 in the appendix, where also the effects of the volatility of liquidity, measured as changes in $\eta_{b}$ and $\eta_{g}$, are shown.
} 
Figure 5: Change in $\left(\hat{x}_{b}^{*}, \hat{x}_{g}^{*}\right)$ due to increase in government's expected liquidity from $\theta_{g}^{0}$ to $\theta_{g}^{0^{\prime}}$.

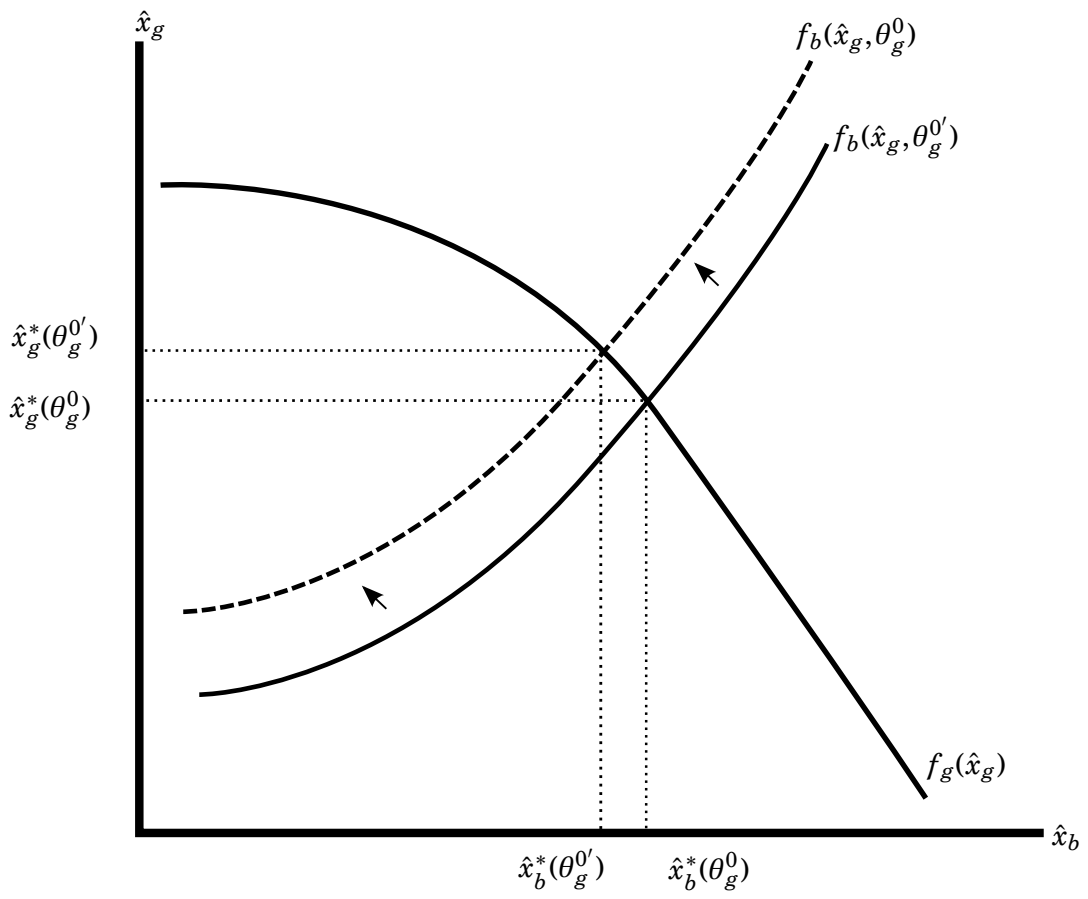

$\operatorname{as}^{8}$

$$
P_{b}(\ell) \equiv \operatorname{Pr}\left(\theta_{b}<\hat{\theta}_{b}^{*}(\ell)\right) \quad \text { and } \quad P_{g}(\ell) \equiv \operatorname{Pr}\left(\theta_{g}<\hat{\theta}_{g}^{*}\left(\ell, \theta_{b}\right)\right)
$$

and

$$
q(\ell) \equiv \operatorname{Pr}\left(\left\{\theta_{b}<\hat{\theta}_{b}^{*}(\ell)\right\} \cap\left\{\theta_{g}<\hat{\theta}_{g}^{*}\left(\ell, \theta_{b}\right)\right\}\right)
$$

respectively.

Fig. 6 illustrates the different regions of crises in $\theta_{b}-\theta_{g}-$ space. By virtue of the uniform distribution assumption, the probabilities can be easily read off the figure as the size of the respective areas. The figure also shows the impact of the guarantee on the default points $\hat{\theta}_{g}^{*}\left(\ell, \theta_{b}\right)$ and $\hat{\theta}_{b}^{*}(\ell)$ for the case where condition (11) holds. The dotted lines separate the regions of default and survival in absence of the guarantee. The introduction of a guarantee $\ell$ shifts the bank's default point to the left (dashed line) and enlarges the region where the bank survives. Moreover, as the guarantee increases, the dotted horizontal line moves to the solid line, increasing the region where the government defaults. Higher guarantee payments, coming due in case of a bank default, make sovereign creditors less willing to roll over and therefore raise their critical signal. This, in turn, raises the government's failure point $\hat{\theta}_{g}$ for all realisations of $\theta_{b}$. In addition, the actual guarantee payments of the government depend on the realized $\theta_{b}$. If the bank defaults (to the left of the dashed line), the government must pay the guarantee to those bank creditors who rolled over. The fraction of bank creditors becoming eligible for the guarantee is increasing in $\theta_{b}$. Thus, guarantee payments are increasing in $\theta_{b}$ and as a consequence the solid line slopes upwards unless bank liquidity is sufficient to avoid a default.

When determining the size of its guarantee, the government faces a trade-off: On the one hand, a higher guarantee lowers the likelihood of and thus the expected costs from

\footnotetext{
${ }^{8}$ We write the equilibrium critical signals as $\hat{x}_{b}^{*}(\ell)$ and $\hat{x}_{g}^{*}(\ell)$ to emphasize their dependency on the guarantee $\ell$. The default points of the government and the bank are written as $\hat{\theta}_{b}^{*}(\ell) \equiv \hat{\theta}_{b}\left(\hat{x}_{b}^{*}(\ell)\right)$ and $\hat{\theta}_{g}^{*}\left(\ell, \theta_{b}\right) \equiv \hat{\theta}_{g}\left(\hat{x}_{g}^{*}(\ell), \hat{x}_{b}^{*}(\ell), \theta_{b}\right)$.
} 
Figure 6: Regions of bank and/or sovereign default in $\theta_{b}-\theta_{g}-$ space. Changes in $\ell$ cause $\hat{\theta}_{b}$ to shift via the shift in $\hat{x}_{b}$. With respect to the likelihood of government default, the change in $\ell$ induces a level-shift in $\hat{\theta}_{g}\left(\ell, \theta_{b}\right)$ and a direct effect because of the dependency on $\theta_{b}$. This creates a functional interdependence between the likelihood of a government default and the bank's liquidity. Calculating the government's probability of default therefore requires integration over both $\theta_{b}$ and $\theta_{g}$.

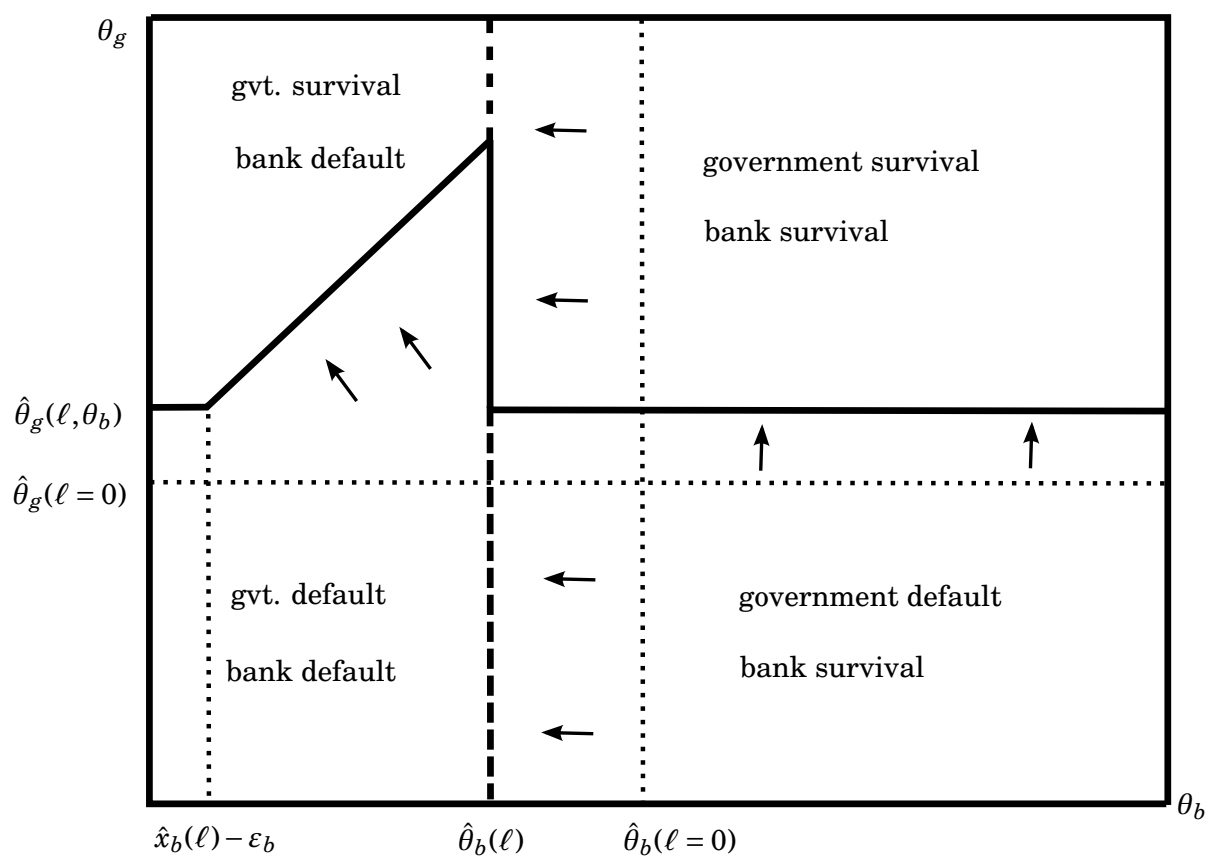

a bank default. On the other hand, it places additional strains on the government's own budget, thus increasing the likelihood of and the expected costs from government default. To model this formally and to derive the optimal guarantee, that solves this trade-off, we define a simple measure for the expected costs of crises.

Let $\phi_{b}$ denote the costs incurred when the bank defaults and the government survives. Similarly, let $\phi_{g}$ denote the costs of a sovereign default, when the bank survives. Finally, the costs of a joint crisis (i.e., a crisis where both government and bank default) are denoted $\phi_{s}$. We normalize all costs by setting $\phi_{s} \equiv 1$. These costs can be interpreted as the loss in the economy's output that materializes following a default event. In particular, $\phi_{b}$ may result from a disruption in financial intermediation and the reduction in available bank credit in the aftermath of default. Banks typically make sizable investments into screening and monitoring technologies, while building long-term relationships with borrowers. Following a bank default, the soft information accrued is lost and has to be acquired anew, which involves costs for the economy as a whole. Moreover, due to the specificity of this information, some of the bank's borrowers cannot easily find a new bank and may become credit constrained. Such constraints may become binding for households and small businesses which, faced with high costs when attempting to borrow on financial markets directly, are highly dependent on financial intermediation via the banking sector. ${ }^{9}$

Equivalently, $\phi_{g}$ is the foregone output due to a sovereign default. The default may impose reputation costs on the government, implying higher borrowing costs in the future or even a full exclusion from financial markets. A government default may also exert a negative effect on trade through either sanctions and retaliations, or reduced access to trade credit. Moreover, empirically, sovereign default is also associated with an

\footnotetext{
${ }^{9}$ See, for example, Leland and Pyle (1977) and Allen and Gale (2001).
} 
immediate effect on economic growth in the default period. ${ }^{10}$

Denoting by $K(\ell)$ the expected default costs, the government's objective at date 0 is to

$$
\min _{\{\ell \in[0,1]\}} K(\ell) \equiv \phi_{g}\left(P_{g}(\ell)-q(\ell)\right)+\phi_{b}\left(P_{b}(\ell)-q(\ell)\right)+q(\ell),
$$

where $P_{g}(\ell), P_{b}(\ell)$ and $q(\ell)$ are defined in the previous section.

In the numerical analysis below, we compare the expected costs under the optimally chosen guarantee denoted by $K^{o p t} \equiv K\left(\ell^{o p t}\right)$ to two benchmarks, (i) the first-best outcome $K^{F B}$ that occurs in the absence of coordination risks for both sovereign and bank creditors, and (ii) the costs $K^{0} \equiv K(0)$ incurred in the absence of a guarantee.

The first-best outcome is obtained if the government and the bank default if and only if $\theta_{b}$ and $\theta_{g}$ are less than zero, i.e. when they are fundamentally insolvent. No coordination failures due to strategic uncertainty would occur and creditors would always choose to roll over for states where bank and government are solvent. Due to the uniform distribution assumption, the first-best benchmark can be calculated as

$$
K^{F B}=\phi_{g} \frac{\left(\eta_{g}-\theta_{g}^{0}\right)}{\sigma_{g}}+\phi_{b} \frac{\left(\eta_{b}-\theta_{b}^{0}\right)}{\sigma_{b}}+\left(1-\phi_{g}-\phi_{b}\right) \frac{\left(\eta_{b}-\theta_{b}^{0}\right)}{\sigma_{b}} \frac{\left(\eta_{g}-\theta_{g}^{0}\right)}{\sigma_{g}} .
$$

While $K^{F B}$ provides a floor to the expected costs of crises, the ceiling is given by the costs incurred in absence of a guarantee, ${ }^{11}$

$$
\begin{aligned}
K^{0}= & K^{F B}+\phi_{g} \frac{C_{g} / D_{g}}{\sigma_{g}}+\phi_{b} \frac{N_{b} / D_{b}}{\sigma_{b}} \\
& +\left(1-\phi_{g}-\phi_{b}\right) \frac{\left(C_{g} / D_{g}+\eta_{g}-\theta_{g}^{0}\right)\left(N_{b} / D_{b}+\eta_{b}-\theta_{b}^{0}\right)-\left(\eta_{g}-\theta_{g}^{0}\right)\left(\eta_{b}-\theta_{b}^{0}\right)}{\sigma_{g} \sigma_{b}}
\end{aligned}
$$

\subsection{The effects of transparency}

The analysis so far has presumed non-zero values for $\varepsilon_{b}$ and $\varepsilon_{g}$, the degrees of transparency of bank and government. Albeit an important parameter, the government's transparency is not as crucial for the effects of the guarantee as the bank's transparency. To appreciate the importance of the latter, consider the extreme case when the bank becomes fully transparent and $\varepsilon_{b} \rightarrow 0$. In this case, as can be immediately seen from Eq. (5), the bank's failure point $\hat{\theta}_{b}$ converges to the critical signal $\hat{x}_{b}$. As bank creditors obtain essentially noise-free information about the bank's liquidity, they almost perfectly coordinate and no creditor makes the mistake to roll over when the bank defaults. Hence, the payoffs to bank creditors are either $D_{b}$ (if everyone rolls over) or $C_{b}$ (if everyone withdraws). While the guarantee payment $\ell$ still raises the creditors' incentives to roll over, it is almost never paid out. The government could therefore issue a large guarantee and effectively reduce the likelihood of default without having to follow up on its promises. In fact, condition (11) is always satisfied and the expected costs of the guarantee for the government are zero.

This changes, however, with a lower degree of balance-sheet transparency and bank creditors facing fundamental uncertainty, i.e. $\varepsilon_{b}>0$. Some creditors may now decide to roll over their loans due to 'misleading' signals $x_{n_{b}}>\hat{x}_{b}$, even though $\theta_{b}<\hat{\theta}_{b}$ and the bank defaults. These creditors become benefactors of the guarantee scheme and receive

\footnotetext{
${ }^{10}$ See, for example, Eaton and Gersovitz (1981) and Borensztein and Panizza (2009).

${ }^{11}$ The respective failure thresholds can be derived from the formula provided in footnote 4 .
} 
$\ell$. Fig. 7 plots $\lambda_{b}$ and the fraction of creditors making the wrong decision and claiming the guarantee, denoted by $\gamma_{b}$, against the fundamental $\theta_{b}$ for the cases of full balancesheet transparency, $\epsilon_{b}=0$ (dashed lines), and lower transparency, $\epsilon_{b}>0$ (solid lines). ${ }^{12}$

Figure 7: Upper diagram: Fraction of bank creditors who withdraw, $\lambda_{b}$. Lower diagram: Fraction of bank creditors who receive guarantee payment, $\gamma_{b}$. The case $\varepsilon_{b}=0$ is represented by the dotted lines, whereas the case $\varepsilon_{b}>0$ is represented by solid lines. An increase in $\varepsilon_{b}$ does not affect $\hat{\theta}_{b}$, but it changes $\hat{x}_{b}$ to $\hat{x}_{b}^{\prime}$. The diagram is drawn under the assumption that $\hat{x}_{b}^{\prime}<\hat{\theta}_{b}$ if $\varepsilon_{b}>0$.

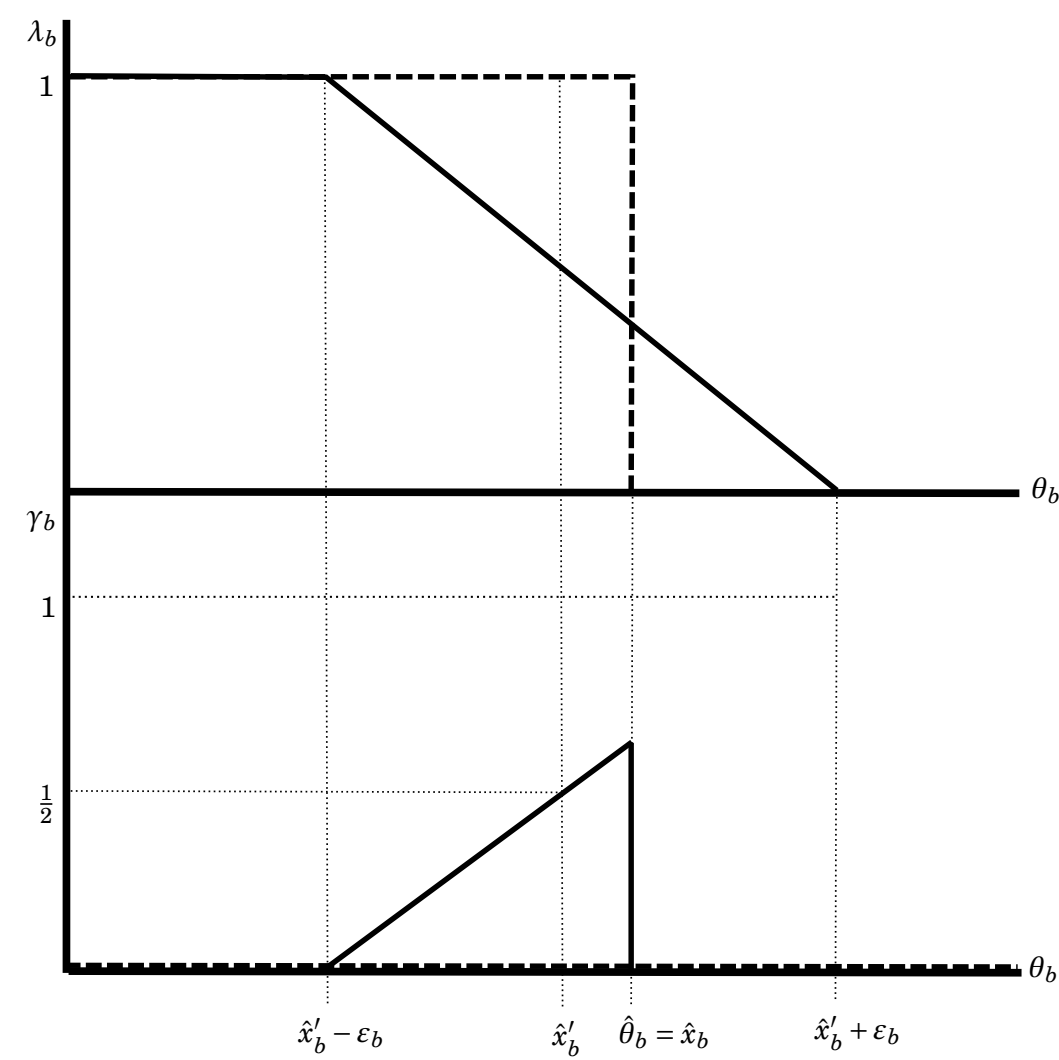

In the case of full transparency, $\lambda_{b}$ is a step function with a jump discontinuity at $\hat{\theta}_{b}$, while $\gamma_{b}$ is always equal to 0 . With lower transparency, however, $\lambda_{b}$ decreases linearly from 1 to 0 over the range $\left[\hat{x}_{b}-\varepsilon_{b}, \hat{x}_{b}+\varepsilon_{b}\right]$, with $\gamma_{b}$ increasing linearly in $\theta_{b}$ from 0 to $\left(\hat{\theta}_{b}-\hat{x}_{b}+\varepsilon_{b}\right) / 2 \varepsilon_{b}$ over the range $\left[\hat{x}_{b}-\varepsilon_{b}, \hat{\theta}_{b}\right]$. The increase in $\gamma_{b}$ illustrates the potential costs stemming from the guarantee scheme. The ex ante expected fraction of agents who benefit from the guarantee, and hence the expected costs for the government, rise when the bank becomes less transparent. When balance-sheet transparency is rather low, creditors' information is widely dispersed and many creditors may erroneously believe that the bank will not default even if, in fact, it does. These creditors, in turn, become eligible for the guarantee payment.

\footnotetext{
${ }^{12} \mathrm{By}$ the law of large numbers, $\gamma_{b}$ equals the probability that a single signal $x_{n_{b}}$ is above $\hat{x}_{b}$ conditional on the realized $\theta_{b}$ and we can write it as

$$
\gamma_{b}\left(\theta_{b}, \hat{x}_{b}, \hat{\theta}_{b}\right)= \begin{cases}0 & \text { if } \theta_{b}>\hat{\theta}_{b} \\ \frac{\theta_{b}-\hat{x}_{b}+\varepsilon_{b}}{2 \varepsilon_{b}} & \text { if } \hat{x}_{b}-\varepsilon_{b}<\theta_{b}<\hat{\theta}_{b} \\ 0 & \text { if } \theta_{b}<\hat{x}_{b}-\varepsilon_{b} .\end{cases}
$$


This begs the question how the optimal guarantee $\ell^{*}$ depends on the degree of bank's balance sheet transparency. The discussion suggests that $\ell^{*}$ converges to its largest possible value for $\varepsilon_{b} \rightarrow 0$. Indeed, in the limit with $\varepsilon_{b} \rightarrow 0$, the derivative of the cost of crises function with respect to $\ell$ becomes,

$$
K^{\prime}(\ell)=-\frac{N_{b}}{\sigma_{b}} \frac{\left(1-P_{g}\right)\left(D_{b}-1\right)}{\left(D_{b}-\ell\left(1-P_{g}\right)\right)^{2}}\left(\left(1-P_{g}\right) \phi_{b}+P_{g}\left(1-\phi_{g}\right)\right)<0,
$$

where we have used the fact that the default points of bank and government in this case are given by

$$
\hat{\theta}_{b}^{*}(\ell)=\frac{N_{b}\left(1-\ell\left(1-P_{g}\right)\right)}{D_{b}-\ell\left(1-P_{g}\right)} \quad \text { and } \quad \hat{\theta}_{g}^{*}=\frac{C_{g}}{D_{g}}
$$

and where $P_{g}=\left(C_{g} / D_{g}+\left(\eta_{g}-\theta_{g}^{0}\right)\right) / \sigma_{g}$.

From Eq. (16) follows that in this case, the government's optimal choice is to provide the maximum guarantee $\ell^{*}=1$. However, in contrast to the conclusion of, for example, Bebchuk and Goldstein (2010) even a full coverage of bank liabilities in our model does not achieve the first-best outcome for the banking sector, because the government may still default with positive probability which puts a limit to the credibility of the guarantee. Hence, even the largest possible guarantee is not sufficient to fully eliminate all inefficient bank defaults and $\hat{\theta}\left(\ell^{*}=1\right)>0$. In order for the bank's default point to equal zero such that only insolvent banks default, the government would need to offer a guarantee that compensates bank creditors for the risk of government default. Thus, the government would have to promise a guarantee that exceeds the face value of bank debt, i.e. the guarantee must be at least as large as $1 /\left(1-P_{g}\right)>1$. Such a guarantee, promising more than $100 \%$ face value would, of course, raise moral-hazard issues in the ex ante provision of credit to banks. Hence, given that the size of the guarantee is restricted to cover at most $100 \%$ of the face value of debt, inefficient runs cannot be entirely avoided even if the bank and the government are fully transparent. Even under a regime of full transparency, there always remains a positive, albeit small, probability that the government defaults, implying that even a maximal full-coverage guarantee is insufficient to stave off bank runs.

Further analytical results with respect to the solution to the government's program and its dependency on the degrees of bank and government transparency are, unfortunately, not possible to obtain. Even though conceptually simple, the government's program does not yield tractable analytical solutions. We therefore resort to a numerical analysis in order to determine the optimal guarantee, and examine its dependency on the degrees of transparency and on the bank's exposure to short-term debt.

\section{Numerical exercises}

We conduct our numerical analysis for calibrations that may loosely resemble some European countries during the recent crisis. Yet, since our model is in reduced form, its stylized nature precludes in-depth case studies and cross-country analyses. Instead, we explore numerically the comparative statics properties. In particular, we are interested in how the optimal guarantee depends on the output losses associated with the different forms of crises, on the relative size of the banking sector, and on the degrees of transparency. 


\subsection{Calibration}

Payoff Parameters. We assume that the risk premium for the bank is higher than the risk premium for the sovereign. This assumption seems consistent with the situation throughout much of Europe prior to the crisis. We thus set $D_{b}=1.75$ and $D_{g}=1.5$. Moreover, for simplicity, we set $C_{b}=C_{g}=1$.

Exposure to Roll-Over Risk. As a benchmark for $N_{b}$, we can resort to the case of Ireland whose banking sector's liabilities were amongst the largest in Europe. At the time when Ireland's first guarantee guarantee scheme was implemented in October 2008, the liabilities of Irish banks that fell under the guarantee amounted roughly to 200 percent of Irish GDP. With respect to the short-term refinancing needs we assume that around $25 \%$ of bank's total liabilities have to be refinanced, which seems in line with numbers provided by International Monetary Fund (2011). Given the size of the Irish banking sector, this roughly equates to refinancing needs in the order of 50 percent of GDP. In contrast, we assume refinancing needs of the government of only 20 percent of GDP, again somewhat in line with International Monetary Fund (2011). This implies that the amount of maturing claims of Irish banks was approximately two and a half times that of the Irish government. Thus, continuing with our normalization of $N_{g}=1$, as an extreme case we set $N_{b}=3$. While this is slightly larger than what current data suggests, we further conduct comparative statics where we vary $N_{b}$ over the range [1,3] for fixed degrees of transparency $\varepsilon_{b}$ and $\varepsilon_{g}$.

For the solution to the government's choice of $\ell^{\text {opt }}$ to exist, we must ensure that the dominance regions of the rollover games are well-defined when $N_{b}=3$. We therefore take $\eta_{b}=5.51, \eta_{g}=3.01, \theta_{b}^{0}=3 / 2$ and $\theta_{g}^{0}=2$. Consequently, the banking sector is exposed to a large rollover risk with expected liquidity $\theta_{b}^{0}$ covering only 50 percent of total maturing claims. For the government, in contrast, expected liquidity is double the amount of maturing claims. ${ }^{13}$

Cost of Crises. In what follows we normalize the cost of a systemic crisis to $\phi_{s}=1$ and concentrate on cases where $\phi_{b}+\phi_{g}<1$. This is justified by the assumption that joint crises, where both the banking sector and the government fail, are considerably more costly than the individual crises together. For calibrating $\phi_{b}$ and $\phi_{g}$, we draw on historical evidence of output losses following banking and sovereign crisis in developed countries. A key challenge here is to identify the banking and sovereign debt crises that occurred independently. Table 3 presents several well-known literature sources and their respective estimates. ${ }^{14}$ The cumulative output losses associated with a joint crisis amount to roughly 54 percent of pre-crisis GDP. The output loss of only sovereign default is at around 10 percent of GDP. Estimated losses due to a solo banking crisis range from 6.3 to 28 percent of GDP. To deal with the range of costs of banking crises, in the first exercise, we set $\phi_{g}=0.2$ (which approximates $\frac{10 \%}{54 \%}=0.185 \approx 0.2$ ) and $\phi_{b}=0.1$ (approximating $\frac{6.3 \%}{54 \%}=0.116 \approx 0.1$ ). In the second exercise, we maintain the value of $\phi_{g}$, but we change $\phi_{b}$ to $0.5 \approx \frac{28 \%}{54 \%}$.

\footnotetext{
${ }^{13}$ The choices of $\eta_{b}$ and $\theta_{b}^{0}$ allow for variations of $\varepsilon_{b}$ up to 2 , whereas the choices of $\eta_{g}$ and $\theta_{g}^{0}$ allow for variations of $\varepsilon_{g}$ up to 0.5 . As mentioned in the preceding section, the choice of $\varepsilon_{g}$ is less important for the outcome of the model, which is why we restrict ourselves to a limited range of variations in this parameter.

${ }^{14} \mathrm{~A}$ recent, important contribution is Valencia and Laeven (2012) who identify a total of 148 banking crises in advanced, emerging and developing countries between 1970 and 2011. Of these, they identify 99 instances as banking-only crises. However, their estimates of output losses use all instances of banking crises.
} 


\begin{tabular}{|c|c|c|c|}
\hline Source & Crisis & Duration & $\begin{array}{c}\text { Avg Annual } \\
\text { Output Loss }\end{array}$ \\
\hline Hoggarth et al. (2002) & Banking & 3.2 & $1.9 \%$ \\
\hline Honohan and Klingebiel (2000) & Banking & 3.5 & $3.6 \%$ \\
\hline Hutchison and Noy (2005) & Banking & 3.3 & $3.0 \%$ \\
\hline De Paoli et al. (2009) & Sovereign & 4 & $2.5 \%$ \\
\hline De Paoli et al. (2009) & Joint (Sovereign and Banking) & 11 & $4.9 \%$ \\
\hline Boyd et al. (2005) & Banking & 5.1 & $5.4 \%$ \\
\hline
\end{tabular}

Table 3: Costs of different types of crises. Output loss in percent of annual GDP. Reported values are the average losses reported in the respective studies.

\subsection{Results}

For our calibrated model we estimate the optimal guarantee by solving the government's optimization routine numerically. We define the associated welfare gain as the difference in the cost of crises without a guarantee $(\ell=0)$ and with the optimal guarantee $\left(\ell=\ell^{\text {opt }}\right)$, i.e.,

$$
\text { welfare }=K^{0}-K^{o p t} \text {. }
$$

A comprehensive assessment of the guarantee's impact is given by probability differentials of banking, sovereign and joint crises, with and without the optimal guarantee, i.e.,

$$
\Delta P_{b} \equiv P_{b}\left(\ell^{o p t}\right)-P_{b}(0) \text { and } \Delta P_{g} \equiv P_{g}\left(\ell^{o p t}\right)-P_{g}(0),
$$

as well as

$$
\Delta q \equiv q\left(\ell^{o p t}\right)-q(0) \text { and } \Delta Q \equiv Q\left(\ell^{o p t}\right)-Q(0),
$$

where $Q(\ell)$ is the probability that at least one crisis occurs, i.e. $Q(\ell)=P_{b}(\ell)+P_{g}(\ell)-q(\ell)$.

Fig. 8 presents the results of comparative statics exercises with respect to the effect of balance sheet transparency and exposure to short-term debt on the optimal guarantee. As can be seen from Panel (a), a lower degree of transparency in the banking sector (high $\varepsilon_{b}$ ) leads to a decrease in the size of the optimal guarantee when the government's transparency is also low (high $\varepsilon_{g}$ ). When both balance sheets are rather opaque, bank and sovereign creditors are more likely to run. Hence, only smaller guarantees may be credibly supported and the optimal guarantee decreases. As shown in Panel (b), the expected welfare gain obtained by the optimal guarantee is highest when the transparency of banks and government is maximal. Then it amounts to roughly 1.2 percent of GDP $(\approx 0.022 \times 54$ percent $)$. An increase in the government's transparency, by reducing $\varepsilon_{g}$ from 0.5 to 0.05 raises expected welfare by 0.2 to 0.4 percent of GDP. Panels (c)-(f) show how the probability differentials $\Delta Q, \Delta q, \Delta P_{b}$ and $\Delta P_{g}$ vary with $\varepsilon_{b}$ and $\varepsilon_{g}$. The introduction of the optimal guarantee leads to an increase in the probability of a sovereign crisis, i.e., $\Delta P_{g}$ increases. This increase is, in absolute magnitude, smaller than the decrease in the probability of a banking crisis. Consequently, the probability of a joint crisis also decreases. Higher bank balance sheet transparency enhances the effects of the guarantee on probabilities $P_{b}, q$ and $Q$, while it has a non-monotone effect on $P_{g}$. In the limit for $\varepsilon_{b} \rightarrow 0$, the guarantee comes at no cost for the government and therefore exerts no effect on the probability $P_{g}$.

Panels (g) and (h) show the effect of changes in the bank's exposure to short-term debt on the optimal guarantee and the resulting welfare gain from introducing the guarantee. For sufficiently low degrees of balance sheet transparency, the optimal guarantee 
decreases monotonically in $N_{b}$. Moreover, the welfare gain increases with $N_{b}$. These two results suggest that, on the one hand, countries with a banking sector facing a lower liquidity mismatch could issue larger guarantees. On the other hand, the welfare gain from the guarantee is larger when the banking sector is more exposed to potential liquidity problems. Moreover, higher bank balance sheet transparency also magnifies the welfare gain and allows to issue larger guarantees for any value of $N_{b}$. If, however, $N_{b}$ increases beyond the limits given by condition (4), the upper dominance region disappears which opens up the possibility of self-fulfilling bank runs and / or government debt crises. ${ }^{15}$

Fig. 9 shows the numerical results with $\phi_{g}=0.2$ and $\phi_{b}=0.5$, that is, when banking crises are considerably more costly than sovereign crises. Several important differences emerge compared to the previous exercise. First of all, the government finds it optimal to provide a full guarantee for a larger range of $\varepsilon_{b}$ values. Consequently $\Delta P_{b}$ is almost constant for a large range of $\varepsilon_{b}$. In fact, this result holds true for a large number of parameterizations where $\phi_{b}>\phi_{g}$. As banking crises become more expensive relative to sovereign crises, the government's optimal choice is a full guarantee, even though this leads to a pronounced increase in sovereign risk. Secondly, as Panel (c) shows, with low degrees of bank and government balance sheet transparency (high $\varepsilon_{b}$ and $\varepsilon_{g}$ ), the probability of experiencing a joint crisis may rise beyond the levels attained in the absence of a guarantee. This effect is driven by the sharp increase in expected guarantee payments conditional on a bank default relative to the shallow decline in the probability of a banking crisis, cf. Panel (e). To strengthen the intuition behind this result, consider Fig. 6. The reduction in $P_{b}$ is tantamount to a shift in the vertical dotted line to the left. The increase in sovereign risk exerts two effects: it shifts the horizontal dotted line upwards, and it may also pivot the first part of this line upwards due to bank creditors who erroneously roll over. This 'pivoting' becomes stronger with a larger $\varepsilon_{g}$ and raises the probability of a joint crisis, even though the probability of any crisis is lowered.

Furthermore, a robust finding is that the increase in the government's default probability is, in absolute magnitude, smaller than the reduction in the bank's default probability. To some extent, this replicates the empirical behavior of CDS spreads shown in Fig. 1(c). This result suggests a new interpretation of the observed changes in CDS spreads. Recall that under full bank transparency, $\left(\varepsilon_{b} \rightarrow 0\right)$, no guarantee payout will ever come due. This implies that for a relatively high degree of bank transparency, the sovereign's default probability remains almost unchanged when the guarantee is introduced, while the impact on the bank's default probability is large. The guarantee removes strategic uncertainty, thereby serving as a device to coordinate bank creditors on the efficient equilibrium. When the degree of bank transparency becomes smaller, the mass of bank creditors who may eventually claim the guarantee increases and, in case the bank defaults, the guarantee creates an actual cost burden for the government. As a result, the government's default probability begins to increase. The large decrease in CDS spreads across countries in Europe that was observed right after the issuance of bank debt guarantees may mirror the removal of strategic uncertainty among bank creditors. Sovereign CDS spreads increased at the same time, thus suggesting that the corresponding banking

\footnotetext{
${ }^{15}$ The strict upper bound on $N_{b}$ is due to our assumption of a uniform distribution. Morris and Shin (2003) and Hellwig (2002) have shown that for normal distributions, uniqueness of the global-game equilibrium requires private information to be sufficiently precise compared to the commonly known variance of the prior distribution. This result would also apply in our model, where it indicates that the size of the banking sector and its transparency interact in allowing for self-fulfilling bank runs. If the banking sector is large or engages in a large maturity mismatch, then it needs to be even more transparent in order for equilibrium uniqueness to be sustained.
} 
sectors may not have operated under a regime of full transparency. Market participants in sovereign funding markets may have conjectured that the guarantees would create an actual cost for the sovereign and therefore asked for a higher risk premium. However, bank transparency was still sufficiently high to avoid an increase in sovereigns' CDS spreads exceeding the reduction in banks' CDS. 
Figure 8: Comparative statics of $\varepsilon_{b}$ and $\varepsilon_{g}$ with $\phi_{b}=0.1$ and $\phi_{g}=0.2$

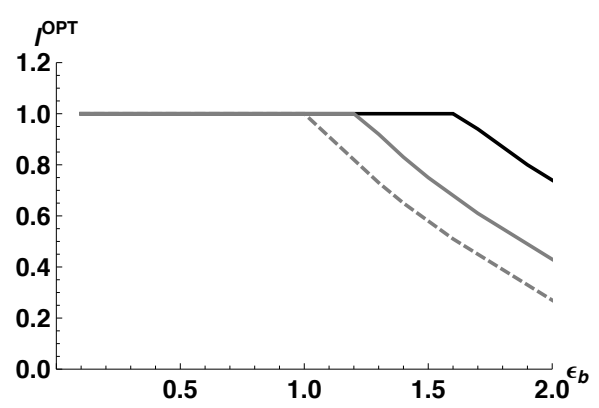

Panel (a): Optimal guarantee: $\ell^{o p t}$

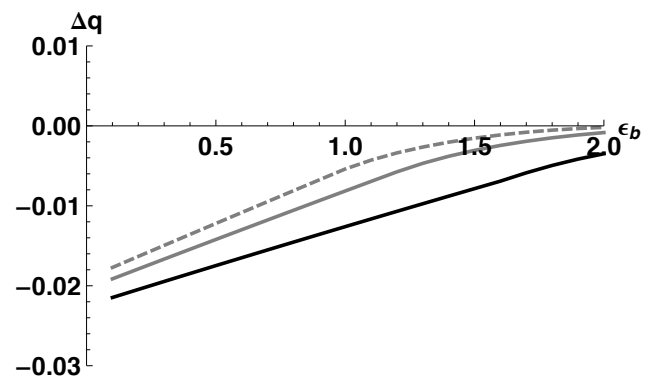

Panel (c): Change in probability of joint crisis: $\Delta q$

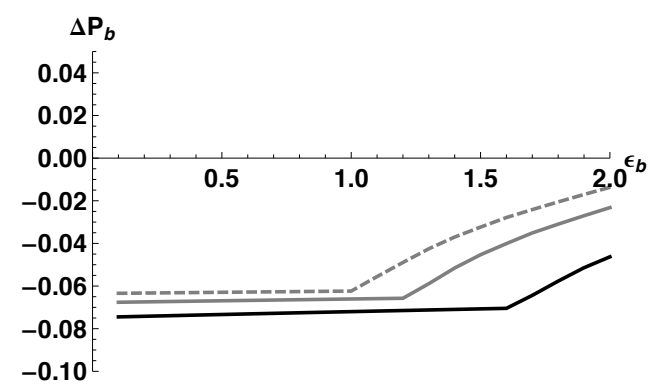

Panel (e): Change in probability of banking crisis: $\Delta P_{b}$

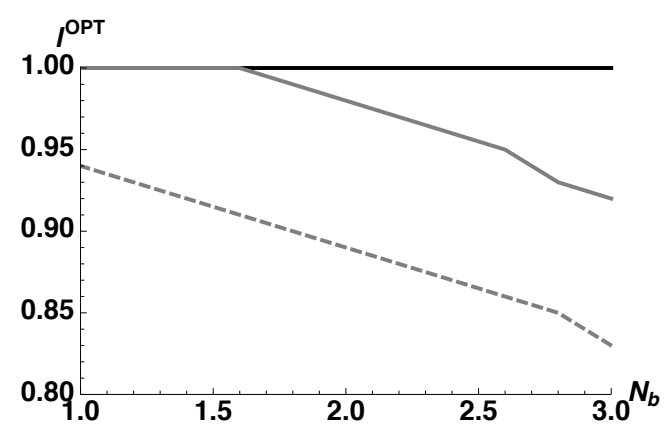

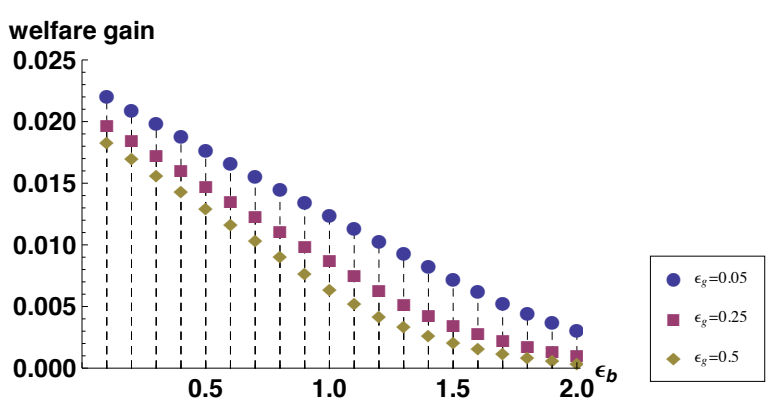

Panel (b): Welfare gain: $K^{0}-K^{o p t}$

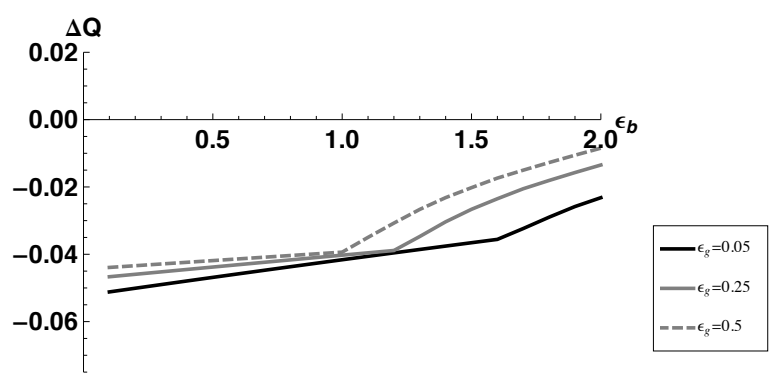

Panel (d): Change in probability of at least one crisis: $\Delta Q$

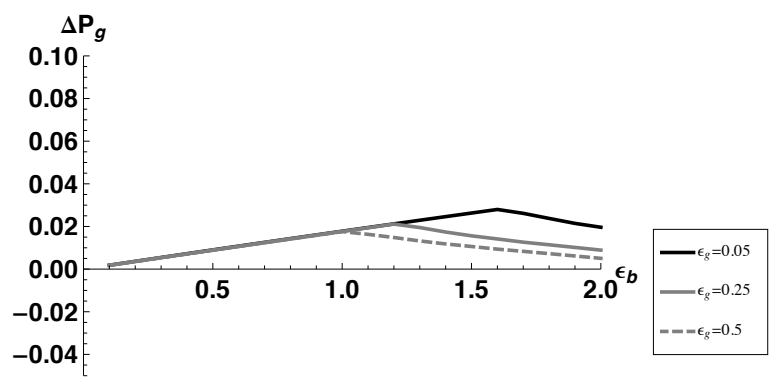

Panel (f): Change in probability of sovereign crisis: $\Delta P g$

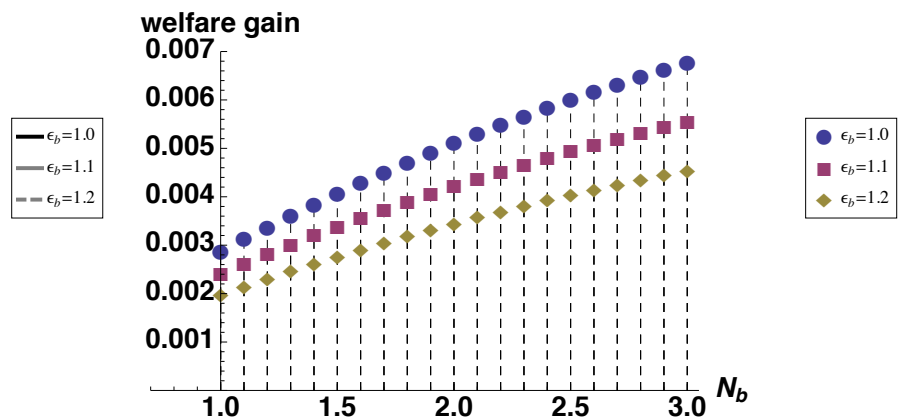

Panel (g): Optimal guarantee $\ell^{o p t}$ as a function of $N_{b}$, for $\varepsilon_{g}=0.5$ and different Panel (h): Welfare gain: $K^{0}-K^{o p t}$ as a function of $N_{b}$, for $\varepsilon_{g}=0.5$ and different values of $\varepsilon_{b}$. 
Figure 9: Comparative statics of $\varepsilon_{b}$ and $\varepsilon_{g}$ with $\phi_{b}=0.5$ and $\phi_{g}=0.2$
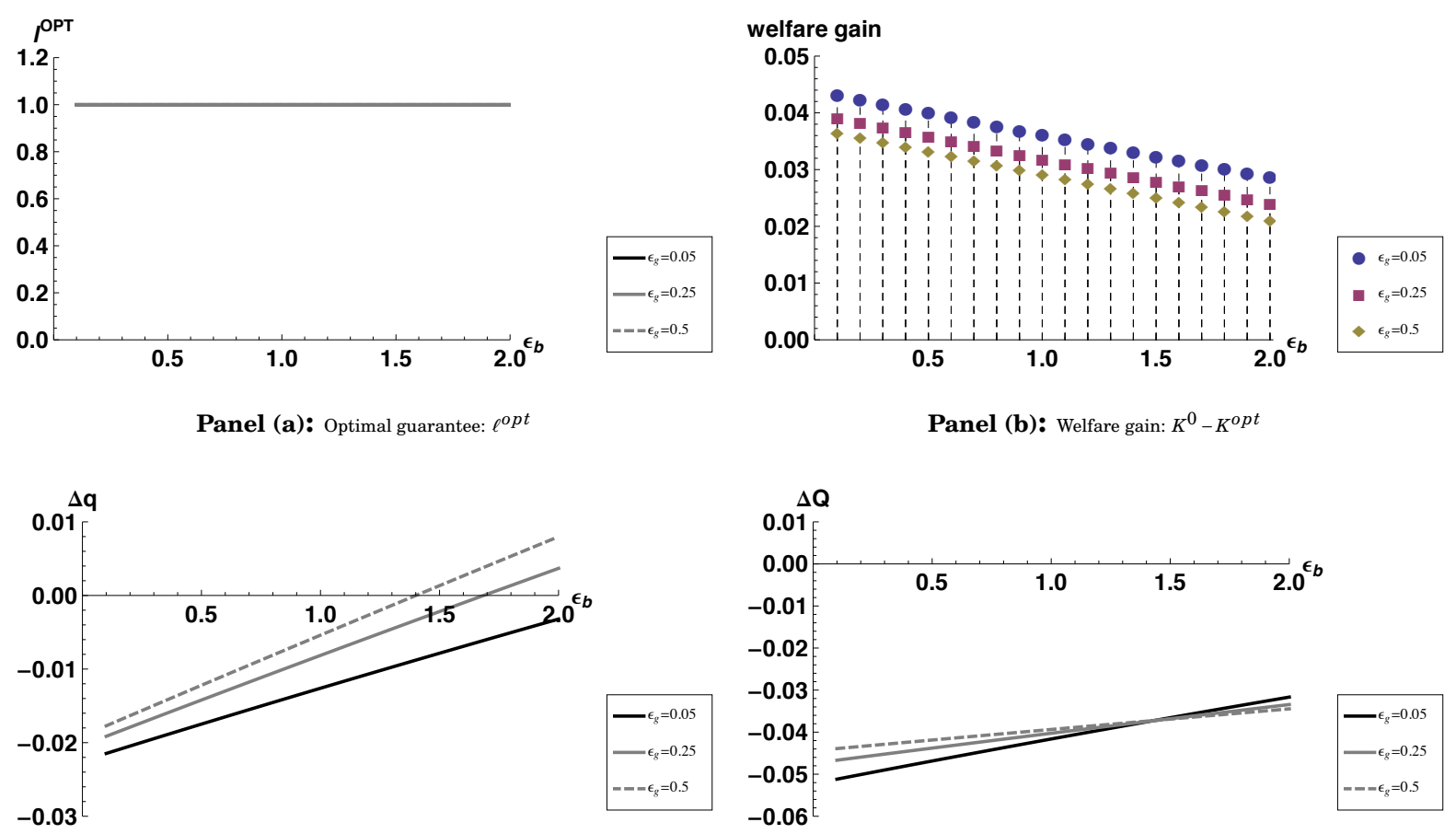

Panel (c): Change in probability of joint crisis: $\Delta q$

Panel (d): Change in probability of at leas one crisis: $\Delta Q$

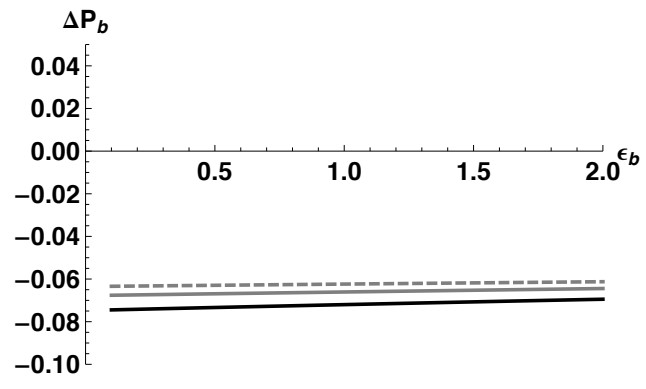

Panel (e): Change in probability of banking crisis: $\Delta P_{b}$

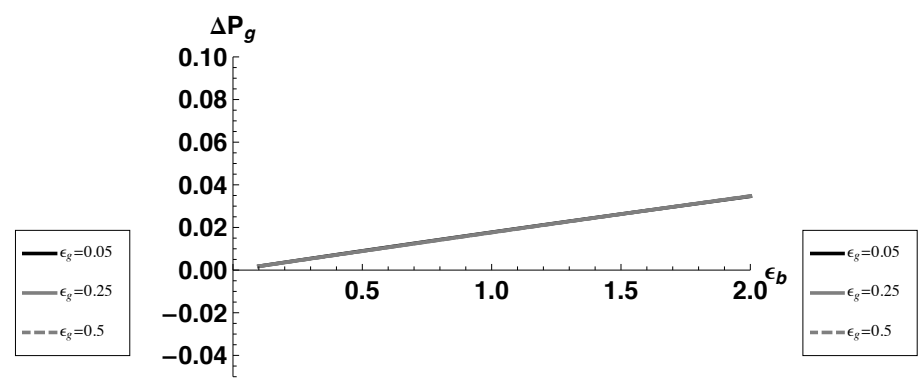

Panel (f): Change in probability of sovereign crisis: $\Delta P_{g}$

\section{Conclusion}

In this paper, we analyzed the effects of a bank debt guarantee by the government and the role of balance sheet transparency in making the guarantee costly. This phenomenon was examined from a 'coordination failure'-perspective by means of a stylized global game. Once bank balance sheet transparency is low, the guarantee promise increases the sovereign's expected liabilities and therefore sovereign creditors become more reluctant to roll over their claims, thereby increasing the government's own likelihood of default. This in turn mitigates the effect of the guarantee on bank creditors' behavior who also become less eager to prolong their funding. What's more, the effectiveness of further increases in the guarantee may even work in the opposite direction by increasing creditors' incentives to withdraw. Proposition 3 provides the respective necessary and sufficient condition for this to occur. Our numerical computations show clear-cut welfare improvements of the guarantee, with greater transparency contributing to lower fundamental uncertainty and higher welfare. This would suggest that, in designing guarantee 
schemes, authorities can improve on their credibility by mandating greater disclosure on the part of the banks. These findings are in line with the new approaches being sought by several countries, as discussed by the Basel Committee for Banking Supervision (2011). Moreover, by improving on the government's own transparency, these gains can be further enhanced. Finally, on grounds of the numerical comparative static results, our model provides a theoretical foundation for the empirically observed behavior of credit default spreads during the recent crisis across the different countries that issued bank debt guarantees.

Albeit being a reduced form model, it captures the key strategic interactions across sovereign and bank creditors. When designing (optimal) guarantee schemes, such effects should be taken into account since they can easily lead to undesirable consequences.

The stark conclusions of the model were obtained not least due to the simplifying assumptions on which it is built and which may deserve closer scrutiny in future work. Firstly, the proof of equilibrium uniqueness rests to a certain extent on the assumption that the bank's and the sovereign's liquidity are independently distributed. This assumption may be challenged, insofar as the recent crisis has demonstrated the close link between banks' and governments' solvency conditions. While we built the model in order to derive the close link between sovereign and bank originating from the government's guarantee promise, a more realistic scenario would probably include a dependency of bank's portfolio quality on sovereign default risk, whereby the 'diabolic loop' would be closed. In such a scenario, the incentives provided by the guarantee to bank creditors would be immediately weakened through the fact that government default would further hamper the bank's solvency. This in turn would strengthen the nature of the strategic effects present in the model. ${ }^{16}$ Secondly, bank and sovereign are modeled in an identical fashion, although in practice, the respective funding markets may work quite differently and sovereign bond owners often exert pressure through a price effect, by selling off government bonds on a secondary market. Thirdly, from a policy perspective it would also be important to understand how bank debt guarantees interact with other measures such as central bank lender of last resort facilities. In the present set-up of our model, such facilities would provide a substitute for bank debt guarantees and would be likely to create the same costs. Finally, the moral hazard implications of higher government guarantees and the associated increase in bank risk-taking, analyzed e.g. in Allen et al. (2013), are another important factor that is so far neglected in our model. Ideally, the functional relationship between government default and banking crises analyzed in the present paper should be combined with moral hazard issues in the provision of short-term credit to banks.

\footnotetext{
${ }^{16}$ This can be explained as follows. On the one hand, if the likelihood of bank default would rise in case the government defaults, then a higher number of sovereign withdrawals would increase bank creditors' incentives to withdraw as well. On the other hand, if more bank creditors withdraw because they believe the government (and hence the bank) to be more likely to default, sovereign creditors' incentives to withdraw decreases because the expected guarantee burden declines. One simple way to incorporate such a feedback from sovereign to bank default is by assuming the bank's threshold to decrease by a constant in case the government defaults. This would create the necessary dependency between bank and sovereign risk to complete the diabolic loop.
} 


\section{References}

Acharya, V. V., Drechsler, I., Schnabl, P., 2011. A pyrrhic victory? bank bailouts and sovereign credit risk, NBER Working Paper No. 17136.

Allen, F., Carletti, E., Goldstein, I., Leonello, A., 2013. Government guarantees and financial stability.

Allen, F., Gale, D., 2001. Comparing Financial Systems. No. 0262511258 in MIT Press Books. The MIT Press.

Bannier, C. E., Heinemann, F., 2005. Optimal transparency and risk-taking to avoid currency crises. Journal of Institutional and Theoretical Economics (JITE) 161 (3).

Basel Committee for Banking Supervision, 2011. Pillar 3 disclosure requirements for remuneration.

Bebchuk, L. A., Goldstein, I., 2010. Self-fulfilling credit market freezes. NBER Working Papers 16031, National Bureau of Economic Research, Inc.

Borensztein, E., Panizza, U., 2009. The costs of sovereign default. IMF Staff Papers 56 (4), $683-741$.

Boyd, J. H., Kwak, S., Smith, B., 2005. The real output losses associated with modern banking crises. Journal of Money, Credit and Banking 37 (6), 977-999.

Carlsson, H., van Damme, E., September 1993. Global games and equilibrium selection. Econometrica 61 (5), 989-1018.

De Paoli, B., Hoggarth, G., Saporta, V., 2009. Output costs of sovereign crises: Some empirical estimates. Bank of England working papers 362, Bank of England.

Diamond, D. W., Dybvig, P. H., 1983. Bank runs, deposit insurance, and liquidity. Journal of Political Economy 91 (3), 401-19.

Eaton, J., Gersovitz, M., 1981. Debt with potential repudiation: Theoretical and empirical analysis. Review of Economic Studies 48 (2), 289-309.

Goldstein, I., 2005. Strategic complementarities and the twin crises. Economic Journal 115 (503), 368-390.

Goldstein, I., Pauzner, A., 2005. Demand deposit contracts and the probability of bank runs. Journal of Finance 60 (3), 1293-1328.

Heinemann, F., Illing, G., 2002. Speculative attacks: unique equilibrium and transparency. Journal of International Economics 58 (2), 429-450.

Hellwig, C., December 2002. Public information, private information, and the multiplicity of equilibria in coordination games. Journal of Economic Theory 107 (2), 191-222.

Hoggarth, G., Reis, R., Saporta, V., 2002. Costs of banking system instability: Some empirical evidence. Journal of Banking \& Finance 26 (5), 825-855.

Honohan, P., 2010. The Irish banking crisis: regulatory and financial stability policy 2003-2008. Tech. rep., Irish Minister for Finance by the Governor of the Central Bank of Ireland. 
Honohan, P., Klingebiel, D., 2000. Controlling the fiscal costs of banking crises. Policy Research Working Paper Series 2441, The World Bank.

Hutchison, M. M., Noy, I., 2005. How bad are twins? output costs of currency and banking crises. Journal of Money, Credit and Banking 37 (4), 725-52.

International Monetary Fund, 2011. Global financial stability report.

Leland, H. E., Pyle, D. H., 1977. Informational asymmetries, financial structure, and financial intermediation. Journal of Finance 32 (2), 371-87.

Levy, A., Schich, S., 2010. The design of government guarantees for bank bonds: Lessons from the recent financial crisis. OECD: Financial Market Trends 2010 (1).

Lindner, A., 2006. Does transparency of central banks produce multiple equilibria on currency markets? Scandinavian Journal of Economics 108 (1), 1-14.

Morris, S., Shin, H. S., 1998. Unique equilibrium in a model of self-fulfilling currency attacks. American Economic Review 88 (3), 587-97.

Morris, S., Shin, H. S., 2000. NBER Macroeconomics Annual. MIT Press, Ch. Rethinking multiple equilibria in macroeconomic modelling, pp. 139 - 161.

Morris, S., Shin, H. S., 2003. Global games: theory and applications. In: Hansen, L. P., Turnovsky, S. J., Dewatripont, M. (Eds.), Advances in Economics and Econometrics. Cambridge University Press, pp. 56-114.

Rochet, J.-C., Vives, X., 2004. Coordination failures and the lender of last resort: Was Bagehot right after all? Journal of the European Economic Association 2 (6), 11161147.

Shao, J., 2003. Mathematical Statistics, 2nd Edition. Springer Texts in Statistics. Springer.

Valencia, F., Laeven, L., Jun. 2012. Systemic banking crises database: An update. IMF Working Papers 12/163, International Monetary Fund.

Wall Street Journal, 2011. Finance ministers agree to EU debt guarantees. online.wsj.com/article/SB10001424052970204012004577070000623643064.html. 


\section{Appendix}

Proof of Proposition 1. Due to the assumption that the random variables $\theta_{b}$ and $\theta_{g}$ are independent, we can consider the roll-over games separately and thereby treat the fundamental and the strategy in the respective other game as exogenously given. As shown in the following Lemmas 1 and 2, for any strategy played by sovereign creditors, bank creditors use a unique threshold strategy. Moreover, as shown in Lemma 3, for any strategy played by bank creditors, sovereign creditors respond by using a unique threshold strategy. As a direct consequence, the unique equilibrium in the model is a threshold equilibrium.

To prove Lemmas 1 - 3, we first introduce some notation and derive some properties of the expected payoff differences of bank and sovereign creditors in Claim 1.

Consider the roll-over game indexed by $i \in\{b, g\}$. Suppose that creditors in the other game play any symmetric strategy $s_{-i}\left(x_{n_{-i}}\right)$. This strategy is independent of $\theta_{i}$ because the signals of creditors in game $-i$ are uninformative about it and the only information available to these creditors is the prior information. We can express the strategy $s_{-i}$ purely as a function of $x_{-i}$. Conditional on $\theta_{-i}$, the fraction of creditors who withdraw in game $-i$ is given by

$$
\lambda_{-i}\left(s_{-i}, \theta_{-i}\right)=\int_{\theta_{-i}-\varepsilon_{-i}}^{\theta_{-i}+\varepsilon_{-i}} s_{-i}\left(x_{n_{-i}}\right) \mathrm{d} x_{n_{-i}} .
$$

Using this notation, the expected payoff difference between rolling over and withdrawing for a typical bank creditor can then be written as

$$
\pi^{b}\left(\theta_{b}, \lambda_{b}, \theta_{g}, s_{g}(\cdot)\right)= \begin{cases}D_{b}-C_{b} & \text { if } \lambda_{b} N_{b}<\theta_{b}, \forall \theta_{g} \\ \ell-C_{b} & \text { if } \lambda_{b} N_{b}>\theta_{b}, N_{g} \lambda_{g}\left(s_{g}, \theta_{g}\right)<\theta_{g}-\left(1-\lambda_{b}\right) N_{b} \ell \\ -C_{b} & \text { if } \lambda_{b} N_{b}>\theta_{b}, N_{g} \lambda_{g}\left(s_{g}, \theta_{g}\right)>\theta_{g}-\left(1-\lambda_{b}\right) \ell\end{cases}
$$

Similarly, the expected payoff difference between rolling over and withdrawing for a typical government creditor can then be written as

$$
\pi^{g}\left(\theta_{g}, \lambda_{g}, \theta_{b}, s_{b}(\cdot)\right)= \begin{cases}D_{g}-C_{g} & \text { if } \lambda_{g} N_{g}<\theta_{g}, N_{b} \lambda_{b}\left(s_{b}, \theta_{b}\right)<\theta_{b} \\ D_{g}-C_{g} & \text { if } \lambda_{g} N_{g}<\theta_{g}-N_{b}\left(1-\lambda_{b}\left(s_{b}, \theta_{b}\right)\right) \ell, N_{b} \lambda_{b}\left(s_{b}, \theta_{b}\right)>\theta_{b} \\ -C_{g} & \text { if } \lambda_{g} N_{g}>\theta_{g}-N_{b}\left(1-\lambda_{b}\left(s_{b}, \theta_{b}\right)\right) \ell, N_{b} \lambda_{b}\left(s_{b}, \theta_{b}\right)>\theta_{b} \\ -C_{g} & \text { if } \lambda_{g} N_{g}>\theta_{g}, \forall \theta_{b}\end{cases}
$$

Claim 1. The expected payoff differences $\pi^{i}, i \in\{b, g\}$, provided in Eqs. (A1) and (A2), satisfy the following properties:

1. $\pi^{b}$ satisfies action single-crossing in $\lambda_{b}$ : For any given $\theta_{b}$ and $\theta_{g}$, there exists $\lambda_{b}^{*}$ such that $\pi^{b}>0$ for any $\lambda_{b}<\lambda_{b}^{*}$ and $\pi^{b}<0$ for any $\lambda_{b}>\lambda_{b}^{*}$.

2. $\pi^{g}$ satisfies action monotonicity in $\lambda_{g}$, i.e. $\pi^{g}$ is non-increasing in $\lambda_{g}$.

3. State monotonicity in $\theta_{i}: \pi^{i}$ is non-decreasing in $\theta_{i}$.

4. Laplacian State Monotonicity: There exists a unique $\theta_{i}^{*}$ such that

$$
\int_{0}^{1} \pi^{i}\left(\theta_{i}^{*}, \lambda_{i}, \theta_{-i}, s_{-i}(\cdot)\right) \mathrm{d} \lambda_{i}=0 .
$$

5. Uniform Limit Dominance: There exist $\underline{\theta}_{i}$ and $\bar{\theta}_{i}$ such that $\pi^{i}<-\delta_{i}$ for $\theta_{i}<\underline{\theta}_{i}$ and $\pi^{i}>\delta_{i}$ for $\theta_{i}>\bar{\theta}_{i}$ for some $\delta_{i}>0$.

Moreover, the noise distributions satisfy

6. Monotone Likelihood Property.

7. Finite expectations of signals.

Proof of Claim 1. 1. Note that $D_{b}-C_{b}>0>\ell-C_{b}>-C_{b}$. Action single-crossing then follows by setting $\lambda_{b}^{*}=\theta_{b} / N_{b}$

2. Since $D_{g}-C_{g}>-C_{g}, \pi^{g}$ is clearly non-increasing in $\lambda_{g}$ for any $\theta_{g}$. This holds independent of whether $\theta_{b}<N_{b} \lambda_{b}$ or $\theta_{b} \geq N_{b} \lambda_{b}$. 
3. Can be inferred immediately from Eqs. (A1) and (A2).

4. For $i=b$, we can write the integral $\int_{0}^{1} \pi^{b}\left(\theta_{b}, \lambda_{b}, \theta_{g}, s_{g}(\cdot)\right) \mathrm{d} \lambda_{b}$ as follows

$$
\begin{aligned}
& \left(D_{b}-C_{b}\right) \int_{0}^{\frac{\theta_{b}}{N_{b}}} \mathrm{~d} \lambda_{b}-C_{b} \int_{\frac{\theta_{b}}{N_{b}}}^{\min \left\{1,1-\left(N_{b} \ell\right)^{-1}\left(\theta_{g}-N_{g} \int_{\theta g}^{\theta_{g}+\varepsilon_{g}} s_{g}\left(x_{n_{g}}\right) \mathrm{d} x_{n g}\right)\right\}} \mathrm{d} \lambda_{b} \\
& +\left(\ell-C_{b}\right) \int_{\min }^{1}\left\{1,1-\left(N_{b} \ell\right)^{-1}\left(\theta_{g}-N_{g} \int_{\theta g}^{\theta-\varepsilon_{g}} s_{g}\left(x_{n_{g}}\right) \mathrm{d} x_{n_{g}}\right)\right\} \\
& \mathrm{d} \lambda_{b} .
\end{aligned}
$$

This expression is negative for $\theta_{b}=0$, positive for $\theta_{b}=N_{b}$ and otherwise strictly increasing in $\theta_{b}$. Hence, there exists a unique $\theta_{b}^{*}$ such that $\int_{0}^{1} \pi\left(\theta_{b}^{*}, \lambda_{b}, \theta_{g}, s_{g}(\cdot)\right) \mathrm{d} \lambda_{b}=0$.

For $i=g$, suppose first $\theta_{b}>N_{b} \lambda_{b}$, then $\theta_{g}^{*}=N_{g} C_{g} / D_{g}$. Secondly, if $\theta_{b}<N_{b} \lambda_{b}$, then $\theta_{g}^{*}=N_{g} C_{g} / D_{g}+$ $N_{b}\left(1-\lambda_{b}\right) \ell$.

5. For $i=b$, the claim follows by setting $\underline{\theta}_{b}=0, \bar{\theta}_{b}=N_{b}$ and $\delta_{b}=\min \left\{C_{b}-\ell, D_{b}-C_{b}\right\}$. For $i=g$, it follows by setting $\bar{\theta}_{g}=N_{g}+N_{b} \ell$ and $\underline{\theta}_{g}=0$ and $\delta=D_{g}-C_{g}$.

6. Both noise terms are uniformly distributed. As shown, for example, by (Shao, 2003, p. 399), the uniform distribution satisfies the MLRP.

7. This follows immediately from the assumption of a uniform distribution with bounded support.

Lemma 1. For any strategy $s_{g}(\cdot)$ played by government creditors, the roll-over game between bank creditors has a unique threshold equilibrium.

Proof of Lemma 1. Since the payoff differential satisfies Properties (1) and (3) to (6) in Claim 1, the lemma follows from Morris and Shin (2003, Lemma 2.3).

Lemma 2. There are no other equilibria where bank creditors use a strategy other than a threshold strategy.

Proof of Lemma 2. Since noise terms are uniformly distributed and the payoff differential satisfies action single-crossing, the lemma follows immediately from the proof to Goldstein and Pauzner (2005, Theorem 1).

Lemma 3. For any strategy $s_{b}(\cdot)$ played by bank creditors, the roll-over game between government creditors has a unique equilibrium in threshold strategies. Moreover, there are no equilibria in non-threshold strategies.

Proof of Lemma 3. Since the payoff differential satisfies Properties (2) to (6) in Claim 1, the lemma follows immediately from Morris and Shin (2003, Proposition 2.2).

Proof of Proposition 2. From the proof of Proposition 1 follows that each game has a unique equilibrium in threshold strategies. That is, for given $\hat{x}_{g}$, there exists a unique $\hat{x}_{b}$ that satisfies Eq. (9) and for given $\hat{x}_{b}$ there exists a unique $\hat{x}_{g}$ that satisfies (10). By the implicit function theorem, there exist functions $f_{b}$ and $f_{g}$ with slopes given by

$$
f_{b}^{\prime}\left(\hat{x}_{g}\right)=-\frac{\partial \pi^{b} / \partial \hat{x}_{g}}{\partial \pi^{b} / \partial \hat{x}_{b}} \quad \text { and } \quad f_{g}^{\prime}\left(\hat{x}_{b}\right)=-\frac{\partial \pi^{g} / \partial \hat{x}_{b}}{\partial \pi^{g} / \partial \hat{x}_{g}} .
$$

Consider the derivative of $\pi^{b}$ with respect to $\hat{x}_{b}$. Observe first that $\hat{\theta}_{b}^{\prime}\left(\hat{x}_{b}\right)=N_{b}\left(N_{b}+2 \varepsilon_{b}\right)^{-1}$ and $(1-$ $\left.\hat{\theta}_{b}^{\prime}\left(\hat{x}_{b}\right)\right)=2 \varepsilon_{b}\left(N_{b}+2 \varepsilon_{b}\right)^{-1}$. Moreover, if $\theta_{b}<\hat{\theta}_{b}$, then $\partial \hat{\theta}_{g} / \partial \hat{x}_{b}=-\ell N_{b} \varepsilon_{g}\left(\varepsilon_{b}\left(1+2 \varepsilon_{g}\right)\right)^{-1}$. Let $\hat{\theta}_{g}^{T} \equiv\left(\hat{x}_{g}+\varepsilon_{g}\right)(1+$ $\left.2 \varepsilon_{g}\right)^{-1}$, so that we can write $\hat{\theta}_{g}\left(\hat{x}_{g}, \hat{x}_{b}, \theta_{b}\right)=\hat{\theta}_{g}^{T}+\frac{\ell N_{b} \varepsilon_{g}}{1+2 \varepsilon_{g}} \frac{\theta_{b}-\hat{x}_{b}+\varepsilon_{b}}{\varepsilon_{b}}$, while $\hat{\theta}_{g}\left(\hat{x}_{g}, \hat{x}_{b}, \hat{x}_{b}-\varepsilon_{b}\right)=\hat{\theta}_{g}^{T}$. Moreover, $\hat{\theta}_{b}-\hat{x}_{b}+\varepsilon_{b}=2 \varepsilon_{b}\left(N_{b}-\hat{x}_{b}+\varepsilon_{b}\right)\left(N_{b}+2 \varepsilon_{b}\right)^{-1}$. Using these facts and definitions, the derivative of $\pi^{b}(\cdot)$ with 
respect to $\hat{x}_{b}$ is given by

$$
\begin{aligned}
& \frac{\partial \pi^{b}\left(\hat{x}_{b}, \hat{x}_{g}, \hat{x}_{b}\right)}{\partial \hat{x}_{b}}=\frac{D_{b}}{2 \varepsilon_{b}}\left(1-\hat{\theta}_{b}^{\prime}\left(\hat{x}_{b}\right)\right)+\frac{\ell}{2 \varepsilon_{b}}\left(\frac{\hat{\theta}_{b}^{\prime}\left(\hat{x}_{b}\right)}{\sigma_{g}} \int_{\hat{\theta}_{g}\left(\hat{x}_{g}, \hat{x}_{b}, \hat{\theta}_{b}\right)}^{\tilde{\sigma}_{g}} \mathrm{~d} v-\frac{1}{\sigma_{g}} \int_{\hat{\theta}_{g}\left(\hat{x}_{g}, \hat{x}_{b}, \hat{x}_{b}-\varepsilon_{b}\right)}^{\widetilde{\sigma}_{g}} \mathrm{~d} v-\int_{\hat{x}_{b}-\varepsilon_{b}}^{\hat{\theta}_{b}} \frac{\partial \hat{\theta}_{g}(\cdot)}{\partial \hat{x}_{b}}\right. \\
& \left.=\frac{D_{b}}{\sigma_{g}} \mathrm{~d} u\right) \\
& =\left(\left(N_{b}+2 \varepsilon_{b}\right) \sigma_{g}\right)^{-1}\left[\sigma_{g} \varepsilon_{b}-\ell\left(\widetilde{\sigma}_{g}-\hat{\theta}_{g}^{T}\right)+\frac{\ell}{2 \varepsilon_{b}}\left(\frac{\ell N_{b} 2 \varepsilon_{g}}{1+2 \varepsilon_{g}}\left(1-\frac{N_{b}}{N_{b}+2 \varepsilon_{b}}\left(\theta_{g}^{0}+\eta_{g}-\hat{\theta}_{g}\left(\hat{\theta}_{b}\right)\right)-\left(\theta_{g}^{0}+\eta_{g}-\hat{\theta}_{g}^{T}\right)+\left(\frac{\ell N_{b} 2 \varepsilon_{g}}{1+2 \varepsilon_{g}} \frac{\left(N_{b}-\hat{x}_{b}+\varepsilon_{b}\right)}{N_{b}+2 \varepsilon_{b}}\right)\right)\right)\right. \\
& =\frac{D_{b}-\ell\left(\frac{\tilde{\sigma}_{g}-\hat{\theta}_{g}\left(\hat{x}_{b}, \hat{x}_{g}, \hat{\theta}_{b}\right)}{\sigma_{g}}\right)}{N_{b}+2 \varepsilon_{b}}>0,
\end{aligned}
$$

because $D_{b}>\ell \geq 0$ and $\frac{\left(\widetilde{\sigma}_{g}-\hat{\theta}_{g}\left(\hat{x}_{b}, \hat{x}_{g}, \hat{\theta}_{b}\right)\right.}{\sigma_{g}} \in[0,1]$ because it is a probability.

And since

$$
\frac{\partial \pi^{b}}{\partial \hat{x}_{g}}=-\frac{\ell}{2 \varepsilon_{b}} \int_{\hat{x}_{b}-\varepsilon_{b}}^{\hat{\theta}_{b}} \frac{1}{\left(1+2 \varepsilon_{g}\right) \sigma_{g}} \mathrm{~d} u<0,
$$

it follows that $f_{b}^{\prime}>0$.

From Eq. (8), the derivative of $\pi^{g}(\cdot)$ with respect to $\hat{x}_{g}$ is given by

$$
\frac{\partial \pi^{g}\left(\hat{x}_{g}, \hat{x}_{b}, \hat{x}_{g}\right)}{\partial \hat{x}_{g}}=\frac{D_{g}}{1+2 \varepsilon_{g}}>0 .
$$

Moreover,

$$
\begin{aligned}
\frac{\partial \pi^{g}}{\partial \hat{x}_{b}} & =-\frac{D_{g} \ell N_{b}}{2 \varepsilon_{b} \sigma_{b}\left(1+2 \varepsilon_{g}\right)} \frac{\partial}{\partial \hat{x}_{b}}\left(\int_{\hat{x}_{b}-\varepsilon_{b}}^{\hat{\theta}_{b}\left(\hat{x}_{b}\right)}\left(u+\varepsilon_{b}-\hat{x}_{b}\right) \mathrm{d} u\right) \\
& =\frac{D_{g} \ell N_{b}}{2 \varepsilon_{b} \sigma_{b}\left(1+2 \varepsilon_{g}\right)}\left(\hat{\theta}_{b}+\varepsilon_{b}-\hat{x}_{b}\right)\left(1-\frac{N_{b}}{N_{b}+2 \varepsilon_{b}}\right)>0 .
\end{aligned}
$$

It follows that $f_{g}^{\prime}<0$.

Lemma 4. The signs of the derivatives of the critical signals $\hat{x}_{b}$ and $\hat{x}_{g}$ with respect to parameters $\left\{\ell, N_{b}, \theta_{b}^{0}, \theta_{g}^{0}, \eta_{b}, \eta_{g}\right\}$ are given by

$$
\begin{aligned}
& \frac{\mathrm{d} \hat{x}_{g}}{\mathrm{~d} \ell}>0, \quad \frac{\mathrm{d} \hat{x}_{b}}{\mathrm{~d} \ell} \lessgtr 0, \quad \frac{\mathrm{d} \hat{x}_{b}}{\mathrm{~d} N_{b}}>0, \quad \frac{\mathrm{d} \hat{x}_{g}}{\mathrm{~d} N_{b}}>0, \frac{\mathrm{d} \hat{x}_{b}}{\mathrm{~d} \theta_{b}^{0}}<0, \quad \frac{\mathrm{d} \hat{x}_{g}}{\mathrm{~d} \theta_{b}^{0}}<0, \quad \frac{\mathrm{d} \hat{x}_{b}}{\mathrm{~d} \theta_{g}^{0}}<0, \quad \frac{\mathrm{d} \hat{x}_{g}}{\mathrm{~d} \theta_{g}^{0}}>0, \\
& \frac{\mathrm{d} \hat{x}_{b}}{\mathrm{~d} \eta_{g}} \lessgtr 0, \quad \frac{\mathrm{d} \hat{x}_{g}}{\mathrm{~d} \eta_{g}} \lessgtr 0, \quad \frac{\mathrm{d} \hat{x}_{b}}{\mathrm{~d} \eta_{b}}<0, \quad \frac{\mathrm{d} \hat{x}_{g}}{\mathrm{~d} \eta_{b}}<0 .
\end{aligned}
$$

Proof of Lemma 4. Denote the vector of exogenous parameters by $\xi=\left(\ell, N_{b}, \theta_{b}^{0}, \theta_{g}^{0}, \eta_{b}, \eta_{g}\right)$ with typical element $\xi_{k}$. The total effects $\frac{\mathrm{d} \hat{x}_{b}}{\mathrm{~d} \xi_{k}}$ and $\frac{\mathrm{d} \hat{x}_{g}}{\mathrm{~d} \xi_{k}}$ can be found by applying the implicit function theorem to the set of equations,

$$
\begin{aligned}
& \pi^{g}\left(\hat{x}_{g}, \hat{x}_{b}, \xi\right)=0 \\
& \pi^{b}\left(\hat{x}_{b}, \hat{x}_{g}, \xi\right)=0 .
\end{aligned}
$$

The Jacobian of this system is given by

$$
\mathbf{J}=\left(\begin{array}{ll}
\frac{\partial \pi^{b}}{\partial \hat{x}_{b}} & \frac{\partial \pi^{b}}{\partial x_{g}} \\
\frac{\partial \pi^{g}}{\partial \hat{x}_{b}} & \frac{\partial \pi^{g}}{\partial \hat{x}_{g}}
\end{array}\right)=\left(\begin{array}{ll}
(+) & (-) \\
(+) & (+)
\end{array}\right),
$$

and thus its determinant is positive, $|\mathbf{J}|>0$.

The total effects can be computed as

$$
\frac{\mathrm{d} \hat{x}_{b}}{\mathrm{~d} \xi_{k}}=\frac{\left|\begin{array}{ll}
-\frac{\partial \pi^{b}}{\partial \xi_{k}} & \frac{\partial \pi^{b}}{\partial \hat{x}_{g}} \\
-\frac{\partial \pi^{g}}{\partial \xi_{k}} & \frac{\partial \pi^{g}}{\partial \hat{x}_{g}}
\end{array}\right|}{|\mathbf{J}|}=\frac{-\frac{\partial \pi^{b}}{\partial \xi_{k}} \frac{\partial \pi^{g}}{\partial \hat{x}_{g}}+\frac{\partial \pi^{b}}{\partial \hat{x}_{g}} \frac{\partial \pi^{g}}{\partial \xi_{k}}}{|\mathbf{J}|} .
$$


and

$$
\frac{\mathrm{d} \hat{x}_{g}}{\mathrm{~d} \xi_{k}}=\frac{\left|\begin{array}{ll}
\frac{\partial \pi^{b}}{\partial x_{b}} & -\frac{\partial \pi^{b}}{\partial \xi_{h}} \\
\frac{\partial \hat{x}^{g}}{\partial \hat{x}_{b}} & -\frac{\partial \pi^{g}}{\partial \xi_{k}}
\end{array}\right|}{|\mathbf{J}|}=\frac{-\frac{\partial \pi^{g}}{\partial \xi_{k}} \frac{\partial \pi^{b}}{\partial \hat{x}_{b}}+\frac{\partial \pi^{g}}{\partial \hat{x}_{b}} \frac{\partial \pi^{b}}{\partial \xi_{k}}}{|\mathbf{J}|}
$$

- Effect of $\ell$ :

From Eqs. (7) and (8), we compute the partial derivatives of $\pi^{b}$ and $\pi^{g}$ with respect to $\ell$ :

$$
\begin{aligned}
\frac{\partial \pi^{b}}{\partial \ell} & =\frac{1}{2 \varepsilon_{b}} \int_{\hat{x}_{b}-\varepsilon_{b}}^{\hat{\theta}_{b}} \frac{1}{\sigma_{g}} \int_{\hat{\theta}_{g}(u)}^{\widetilde{\sigma}_{g}} \mathrm{~d} v \mathrm{~d} u-\frac{\ell}{2 \varepsilon_{b}} \int_{\hat{x}_{b}-\varepsilon_{b}}^{\hat{\theta}_{b}} \frac{\varepsilon_{g} N_{b}}{\varepsilon_{b}\left(1+2 \varepsilon_{g}\right)} \frac{\left(u+\varepsilon_{b}-\hat{x}_{b}\right)}{\sigma_{g}} \mathrm{~d} u \\
& =\frac{1}{2 \varepsilon_{b} \sigma_{g}} \int_{\hat{x}_{b}-\varepsilon_{b}}^{\hat{\theta}_{b}}\left[\int_{\hat{\theta}_{g}(u)}^{\widetilde{\sigma}_{g}} \mathrm{~d} v-\frac{\varepsilon_{g} \ell N_{b}}{\varepsilon_{b}\left(1+2 \varepsilon_{g}\right)}\left(u+\varepsilon_{b}-\hat{x}_{b}\right)\right] \mathrm{d} u \\
& =\frac{1}{2 \varepsilon_{b} \sigma_{g}} \int_{\hat{x}_{b}-\varepsilon_{b}}^{\hat{\theta}_{b}}\left[\widetilde{\sigma}_{g}-\hat{\theta}_{g}^{T}-\frac{2 \varepsilon_{g} \ell N_{b}}{\varepsilon_{b}\left(1+2 \varepsilon_{g}\right)}\left(u+\varepsilon_{b}-\hat{x}_{b}\right)\right] \mathrm{d} u \\
& =\frac{\hat{\theta}_{b}-\hat{x}_{b}+\varepsilon_{b}}{2 \varepsilon_{b}}\left\{\left(\frac{\widetilde{\sigma}_{g}-\hat{\theta}_{g}^{T}}{\sigma_{g}}\right)+\frac{2 \ell \varepsilon_{g} N_{b}\left(\hat{x}_{b}-\varepsilon_{b}\right)}{\sigma_{g} \varepsilon_{b}\left(1+2 \varepsilon_{g}\right)}-\frac{2 \ell \varepsilon_{g} N_{b}\left(\hat{\theta}_{b}+\hat{x}_{b}-\varepsilon_{b}\right)}{2 \sigma_{g} \varepsilon_{b}\left(1+2 \varepsilon_{g}\right)}\right\} \\
& =\frac{\hat{\theta}_{b}-\hat{x}_{b}+\varepsilon_{b}}{2 \varepsilon_{b}}\left\{\frac{\widetilde{\sigma}_{g}-\hat{\theta}_{g}^{T}}{\sigma_{g}}+\frac{\ell \varepsilon_{g} N_{b}\left(\hat{x}_{b}-\varepsilon_{b}-\hat{\theta}_{b}\right)}{\sigma_{g} \varepsilon_{b}\left(1+2 \varepsilon_{g}\right)}\right\} \\
& =\frac{\hat{\theta}_{b}-\hat{x}_{b}+\varepsilon_{b}}{2 \varepsilon_{b}}\left\{\frac{\widetilde{\sigma}_{g}-\hat{\theta}_{g}\left(\hat{\theta}_{b}\right)}{\sigma_{g}}\right\} \geq 0,
\end{aligned}
$$

where we have used the abbreviation $\hat{\theta}_{g}(u):=\hat{\theta}_{g}\left(\hat{x}_{g}, \hat{x}_{b}, u\right)$.

Furthermore,

$$
\frac{\partial \pi^{g}}{\partial \ell}=\frac{-D_{g} N_{b}}{\sigma_{b}\left(1+2 \varepsilon_{g}\right)} \int_{\hat{x}_{b}-\varepsilon_{b}}^{\hat{\theta}_{b}} \frac{u+\varepsilon_{g}-\hat{x}_{b}}{2 \varepsilon_{b}} \mathrm{~d} u<0 .
$$

Given the signs of Eqs. (A9) and (A10), it follows from Eqs. (A7) and (A8) that

$$
\frac{\mathrm{d} \hat{x}_{g}}{\mathrm{~d} \ell}>0 \quad \text { while } \quad \frac{\mathrm{d} \hat{x}_{b}}{\mathrm{~d} \ell} \text { may be positive or negative. }
$$

Condition (11) in the text can be derived by explicitly calculating

$$
-\frac{\partial \pi^{b}}{\partial \ell} \frac{\partial \pi^{g}}{\partial \hat{x}_{g}}+\frac{\partial \pi^{b}}{\partial \hat{x}_{g}} \frac{\partial \pi^{g}}{\partial \ell} .
$$

Using Eqs. (A5), (A4), (A9) and (A10), we obtain

$$
-\frac{D_{g}}{1+2 \varepsilon_{g}}\left(\frac{\hat{\theta}_{b}-\hat{x}_{b}+\varepsilon_{b}}{2 \varepsilon_{b}}\right)\left(\frac{\widetilde{\sigma}_{g}-\hat{\theta}_{g}\left(\hat{\theta}_{b}\right)}{\sigma_{g}}\right)+\left(\frac{\hat{\theta}_{b}-\hat{x}_{b}+\varepsilon_{b}}{2 \varepsilon_{b}}\right) \frac{D_{g} \ell N_{b}}{\sigma_{g} \sigma_{b}\left(1+2 \varepsilon_{g}\right)} \int_{\hat{x}_{b}-\varepsilon_{b}}^{\hat{\theta}_{b}} \frac{u+\varepsilon_{b}-\hat{x}_{b}}{2 \varepsilon_{b}} \mathrm{~d} u .
$$

The latter is negative if and only if

$$
\frac{\ell N_{b}}{\sigma_{b}} \int_{\hat{x}_{b}-\varepsilon_{b}}^{\hat{\theta}_{b}} \frac{u+\varepsilon_{b}-\hat{x}_{b}}{2 \varepsilon_{b}} \mathrm{~d} u<\widetilde{\sigma}_{g}-\hat{\theta}_{g}\left(\hat{\theta}_{b}\right),
$$

which is condition (11) in the main text.

- Effect of $N_{b}$ :

The derivative of $\pi^{b}$ with respect to $N_{b}$ is given by

$$
\begin{aligned}
\frac{\partial \pi^{b}}{\partial N_{b}} & =-\left[\frac{\hat{\theta}_{b}}{N_{b}}\left(\frac{D_{b}-\ell\left(\frac{\tilde{\sigma}_{g}-\hat{\theta}_{g}\left(\hat{x}_{b}, \hat{x}_{g}, \hat{\theta}_{b}\right)}{\sigma_{g}}\right)}{N_{b}+2 \varepsilon_{b}}\right)+\frac{\ell^{2} \varepsilon_{g}\left(\hat{\theta}_{b}-\hat{x}_{b}+\varepsilon_{b}\right)^{2}}{4 \varepsilon_{b}^{2} \sigma_{g}\left(1+2 \varepsilon_{g}\right)}\right] \\
& =-\left[\frac{\hat{\theta}_{b}}{N_{b}} \frac{\partial \pi^{b}}{\partial \hat{x}_{b}}+\frac{\ell^{2} \varepsilon_{g}\left(\hat{\theta}_{b}-\hat{x}_{b}+\varepsilon_{b}\right)^{2}}{4 \varepsilon_{b}^{2} \sigma_{g}\left(1+2 \varepsilon_{g}\right)}\right]<0,
\end{aligned}
$$


where, in the last line, we have substituted Eq. (A3).

The derivative of $\pi^{g}$ with respect to $N_{b}$ is

$$
\begin{aligned}
\frac{\partial \pi^{g}}{\partial N_{b}} & =-\frac{D_{g} \ell}{\sigma_{b}\left(1+2 \varepsilon_{g}\right)} \int_{\hat{x}_{b}-\varepsilon_{b}}^{\hat{\theta}_{b}} \frac{u+\varepsilon_{b}-\hat{x}_{b}}{2 \varepsilon_{b}} \mathrm{~d} u-\frac{D_{g} \ell N_{b}}{\sigma_{b}\left(1+2 \varepsilon_{g}\right)} \frac{\hat{\theta}_{b}+\varepsilon_{b}-\hat{x}_{b}}{2 \varepsilon_{b}} \frac{2 \varepsilon_{b}\left(\hat{x}_{b}+\varepsilon_{b}\right)}{\left(N_{b}+2 \varepsilon_{b}\right)^{2}} \\
& =-\frac{D_{g} \ell\left(\hat{\theta}_{b}-\hat{x}_{b}+\varepsilon_{b}\right)}{\sigma_{b}\left(1+2 \varepsilon_{g}\right)}\left[\frac{\left(\hat{\theta}_{b}-\hat{x}_{b}+\varepsilon_{b}\right)}{4 \varepsilon_{b}}+\frac{\hat{\theta}_{b}}{N_{b}+2 \varepsilon_{b}}\right]<0
\end{aligned}
$$

Given the signs of Eqs. (A12) and (A13), from Eq. (A7) follows $\frac{\mathrm{d} \hat{x}_{b}}{\mathrm{~d} N_{b}}>0$.

To show that $\frac{\mathrm{d} \hat{x}_{g}}{\mathrm{~d} N_{b}}>0$, we explicitly calculate

$$
-\frac{\partial \pi^{g}}{\partial N_{b}} \frac{\partial \pi^{b}}{\partial \hat{x}_{b}}+\frac{\partial \pi^{g}}{\partial \hat{x}_{b}} \frac{\partial \pi^{b}}{\partial N_{b}}
$$

and show that it is positive.

Using Eqs. (A3), (A6), (A12) and (A13), we can write the latter as

$\frac{D_{g} \ell\left(\hat{\theta}_{b}-\hat{x}_{b}+\varepsilon_{b}\right)}{\sigma_{b}\left(1+2 \varepsilon_{g}\right)}\left[\frac{\left(\hat{\theta}_{b}-\hat{x}_{b}+\varepsilon_{b}\right)}{4 \varepsilon_{b}}+\frac{\hat{\theta}_{b}}{N_{b}+2 \varepsilon_{b}}\right] \frac{\partial \pi^{b}}{\partial \hat{x}_{b}}-\frac{D_{g} \ell\left(\hat{\theta}_{b}+\varepsilon_{b}-\hat{x}_{b}\right)}{\sigma_{b}\left(1+2 \varepsilon_{g}\right)}\left[\frac{1}{N_{b}+2 \varepsilon_{b}}\right]\left[\hat{\theta}_{b} \frac{\partial \pi^{b}}{\partial \hat{x}_{b}}+\frac{N_{b} \ell^{2} \varepsilon_{g}\left(\hat{\theta}_{b}-\hat{x}_{b}+\varepsilon_{b}\right)^{2}}{4 \varepsilon_{b}^{2} \sigma_{g}\left(1+2 \varepsilon_{g}\right)}\right]$

The multiplicative term $\frac{D_{g} \ell\left(\hat{\theta}_{b}+\varepsilon_{b}-\hat{x}_{b}\right)}{\sigma_{b}\left(1+2 \varepsilon_{g}\right)}$ can be factored out as it does not affect the sign. Hence, we are left with

$$
\left[\frac{\left(\hat{\theta}_{b}-\hat{x}_{b}+\varepsilon_{b}\right)}{4 \varepsilon_{b}}+\frac{\hat{\theta}_{b}}{N_{b}+2 \varepsilon_{b}}\right] \frac{\partial \pi^{b}}{\partial \hat{x}_{b}}-\left[\frac{1}{N_{b}+2 \varepsilon_{b}}\right]\left[\hat{\theta}_{b} \frac{\partial \pi^{b}}{\partial \hat{x}_{b}}+\frac{N_{b} \ell^{2} \varepsilon_{g}\left(\hat{\theta}_{b}-\hat{x}_{b}+\varepsilon_{b}\right)^{2}}{4 \varepsilon_{b}^{2} \sigma_{g}\left(1+2 \varepsilon_{g}\right)}\right]
$$

This can be further simplified to

$$
\left[\frac{\left(\hat{\theta}_{b}-\hat{x}_{b}+\varepsilon_{b}\right)}{4 \varepsilon_{b}}\right] \frac{\partial \pi^{b}}{\partial \hat{x}_{b}}-\left[\frac{1}{N_{b}+2 \varepsilon_{b}}\right]\left[\frac{N_{b} \ell^{2} \varepsilon_{g}\left(\hat{\theta}_{b}-\hat{x}_{b}+\varepsilon_{b}\right)^{2}}{4 \varepsilon_{b}^{2} \sigma_{g}\left(1+2 \varepsilon_{g}\right)}\right] .
$$

Factoring out $\frac{\left(\hat{\theta}_{b}-\hat{x}_{b}+\varepsilon_{b}\right)}{4 \varepsilon_{b}}>0$, the sign of $\mathrm{d} \pi^{b} / \mathrm{d} N_{b}$ is determined by

$$
\frac{\partial \pi^{b}}{\partial \hat{x}_{b}}-\left[\frac{1}{N_{b}+2 \varepsilon_{b}}\right]\left[\frac{N_{b} \ell^{2} \varepsilon_{g}\left(\hat{\theta}_{b}-\hat{x}_{b}+\varepsilon_{b}\right)}{\varepsilon_{b} \sigma_{g}\left(1+2 \varepsilon_{g}\right)}\right] .
$$

Using Eq. (A3) and factoring out the common denominator, the sign is determined by

$$
\begin{aligned}
& D_{b}-\frac{\ell}{\sigma_{g}}\left(\tilde{\sigma}_{g}-\hat{\theta}_{g}\left(\hat{x}_{b}, \hat{x}_{b}, \hat{\theta}_{b}\right)-\frac{\ell N_{b} \varepsilon_{g}\left(\hat{\theta}_{b}-\hat{x}_{b}+\varepsilon_{b}\right)}{\varepsilon_{b}\left(1+2 \varepsilon_{g}\right)}\right) \\
= & D_{b}-\ell\left(\frac{\tilde{\sigma}_{g}-\hat{\theta}_{g}^{T}}{\sigma_{g}}\right)>0,
\end{aligned}
$$

where the last inequality holds because $\ell<D_{b}$ and $\frac{\tilde{\sigma}_{g}-\hat{\theta}_{g}^{T}}{\sigma_{g}} \in[0,1]$ as it is a probability.

- Effects of $\theta_{b}^{0}$ and $\theta_{g}^{0}$ :

The derivatives with respect to $\theta_{b}^{0}$ and $\theta_{g}^{0}$ are given by

$$
\frac{\partial \pi^{b}}{\partial \theta_{g}^{0}}=\frac{\ell}{2 \varepsilon_{b}} \int_{\hat{x}_{b}-\varepsilon_{b}}^{\hat{\theta}_{b}\left(\hat{x}_{b}\right)} \frac{1}{\sigma_{g}} \mathrm{~d} u>0, \quad \frac{\partial \pi^{b}}{\partial \theta_{b}^{0}}=0, \quad \frac{\partial \pi^{g}}{\partial \theta_{g}^{0}}=0, \quad \frac{\partial \pi^{g}}{\partial \theta_{b}^{0}}=0
$$

Combining these with Eqs. (A7) and (A8), we obtain

$$
\frac{\mathrm{d} \hat{x}_{b}}{\mathrm{~d} \theta_{b}^{0}}=0, \frac{\mathrm{d} \hat{x}_{b}}{\mathrm{~d} \theta_{g}^{0}}<0, \frac{\mathrm{d} \hat{x}_{g}}{\mathrm{~d} \theta_{b}^{0}}=0, \frac{\mathrm{d} \hat{x}_{g}}{\mathrm{~d} \theta_{g}^{0}}>0 .
$$


- Effects of $\eta_{b}$ and $\eta_{g}$ :

The derivatives of $\pi^{b}$ and $\pi^{g}$ with respect to $\eta_{b}$ and $\eta_{g}^{0}$ are given by

$\frac{\partial \pi^{b}}{\partial \eta_{g}}=\frac{\ell}{\varepsilon_{b} \sigma_{g}^{2}} \int_{\hat{x}_{b}-\varepsilon_{b}}^{\hat{\theta}_{b}\left(\hat{x}_{b}\right)}\left(\hat{\theta}_{g}(u)-\theta_{g}^{0}\right) \mathrm{d} u \lessgtr 0, \quad \frac{\partial \pi^{b}}{\partial \eta_{b}}=0, \quad \frac{\partial \pi^{g}}{\partial \eta_{g}}=0, \quad \frac{\partial \pi^{g}}{\partial \eta_{b}}=\frac{D_{g} \ell N_{b}}{\left(1+2 \varepsilon_{g}\right) \sigma_{b}^{2}} \int_{\hat{x}_{b}-\varepsilon_{b}}^{\hat{\theta}_{b}} \frac{u+\varepsilon_{b}-\hat{x}_{b}}{\varepsilon_{b}} \mathrm{~d} u>0$.

Combining these with Eqs. (A7) and (A8), we obtain

$$
\frac{\mathrm{d} \hat{x}_{b}}{\mathrm{~d} \eta_{b}}<0, \frac{\mathrm{d} \hat{x}_{b}}{\mathrm{~d} \eta_{g}} \lessgtr 0, \frac{\mathrm{d} \hat{x}_{g}}{\mathrm{~d} \eta_{b}}<0, \frac{\mathrm{d} \hat{x}_{g}}{\mathrm{~d} \eta_{g}} \gtrless 0 .
$$

Moreover, since bank creditors' actions are strategic substitutes for sovereign creditors, we have that if $\frac{\mathrm{d} \hat{x}_{b}}{\mathrm{~d} \eta_{g}}<0$, then $\frac{\mathrm{d} \hat{x}_{g}}{\mathrm{~d} \eta_{g}}>0$ and vice versa. A sufficient condition for $\frac{\partial \pi^{b}}{\partial \eta_{g}}>0$ and thus $\frac{\mathrm{d} \hat{x}_{b}}{\mathrm{~d} \eta_{g}}<0$ is $\hat{\theta}_{g}^{T}>\theta_{g}^{0}=\mathbf{E}\left(\theta_{g}\right)$.

Proof of Corollary 1. Suppose $\ell=\tilde{\ell}$ and condition (11) holds when evaluated at $\tilde{\ell}$. This implies that $\mathrm{d} \hat{x}_{b}(\tilde{\ell}) / \mathrm{d} \ell<0$.

The derivative of the left-hand side of condition (11) with respect to $\ell$ is given by

$$
\frac{N_{b}}{\sigma_{b}} \int_{\hat{x}_{b}-\varepsilon_{b}}^{\hat{\theta}_{b}} \frac{u+\varepsilon_{b}-\hat{x}_{b}}{2 \varepsilon_{b}} \mathrm{~d} u-\frac{\ell N_{b}}{\sigma_{b}} \cdot \frac{\hat{\theta}_{b}+\varepsilon_{b}-\hat{x}_{b}}{2 \varepsilon_{b}} \frac{2 \varepsilon_{b}}{N_{b}+2 \varepsilon_{b}} \frac{\mathrm{d} \hat{x}_{b}}{\mathrm{~d} \ell},
$$

which is positive by the supposition that (11) holds.

Consider the derivative of the right-hand side with respect to $\ell$. It is given by

$$
-\frac{\frac{\mathrm{d} \hat{x}_{g}}{\mathrm{~d} \ell}}{1+2 \varepsilon_{g}}-\frac{\varepsilon_{g} N_{b}\left(\hat{\theta}_{b}+\varepsilon_{b}-\hat{x}_{b}\right)}{\varepsilon_{b}\left(1+2 \varepsilon_{g}\right)}+\frac{\varepsilon_{g} \ell N_{b}}{\varepsilon_{b}\left(1+2 \varepsilon_{g}\right)} \frac{2 \varepsilon_{b}}{N_{b}+2 \varepsilon_{b}} \frac{\mathrm{d} \hat{x}_{b}}{\mathrm{~d} \ell}
$$

which is negative by the supposition that (11) holds. 